\title{
BASIC RADIO PROPAGATION PREDICTIONS FOR SEPTEMBER 1945
} THREE MONTHS IN ADVANCE

ISSUED

JUNE 1945

PREPARED BY INTERSERVICE RADIO PROPAGATION LABORATORY National Bureau of Standards Washington 25, D. C. 
"This document contains information affecting the national defense of the United States within the meaning of the Espionage Act, 50 U. S. C., 31 and 32. Its transmission or the revelation of its contents in any manner to an unauthorized person is prohibited by law." 
IRPL-D 10

INTERSERVICE RADIO PROPAGATION LABORATORY

Issued

NATIONAL BUREAU OF STANDARDS

1 June 1945

WASHINGTON 25, D. C.

Organized Lnder Joint LT. S. Communications Board

\section{BASIC RADIO PROPAGATION PREDICTIONS FOR SEPTEMBER 1945 THREE MONTHS IN ADVANCE}

The monthy reports of the IRPL-D series are nuw distributed to the Army as the TB 11-499 series, by the Adjutant General; to the Navy as the DNC-13 1 series, by the Registered Publications Seetion, Division of Naval Communications; and to others by the IRPL.
This IRPL-D series is a monthly supplement to the IRPL liadio Propagation Handbook, Part 1, issued by the Army as T M 11-499 and by the Navy as DNC-13-1, and is required in order to make practical application of the basie Handbook.

\section{CONTENTS}

I. Terminology-.

II World-wide predietion charts and their nes Page 2

World map showing zones covered by prediction charts, and auroral zones- Fig. 1

$F$ 2-zero-muf, in Mc, II zone, predieted for September 1945............ Fig. 5

F2-4000-muf, in Me, IT zone, predieted for September 1945_........... Fig. 6

F 2-zero-muf, in Me, I zone, predicterl for September 1945_......... Fig. 7

F2-4000-muf, in Me, I zone, predieted for September $1945 \ldots$ Fig. S

$F 2$-zero-muf, in Mc, $E$ zone, predicted for September 1945_........... Fig.9

F2-4000-muf, in Me, E zone, predicted for September $1945 \ldots$

E-layer 2000-muf, in Mc, predicted for September 1945
Iedian $f E s$, in $M c$, predicted for Ser-

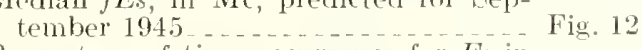

Percentage of time vecurrence for $E_{s}$ in excess of 15 Me, predicted for September 1945 ................. Fig. 15

III. Determination of great-cirele distances, bearings, location of transmission eontrol points, solar zenith angles............ Page 2

Great-eircle chart, centered on equator, with small cireles indicating distanees in kilometers of transmission path auxiliary to explanation of use of distancebearing nomogram, figure 4
Fig. 10 Fig. 11 Fig. 2 Fig. 3
III. Detormination, ete-Continned.

Nomogram for obtaining great-cirele distanees, bearings, latitude and longitude of transmission eontrol points, solar zenith angles. Conversion seate for varions distanee units.........

II. Calculation of maximum usable frequencies and optimum working frequencies_...... Page 3

Nomograms for transforming $F 2$-zeromuf and $F_{2}-4000-m u f$ to equivalent maximum usable frequencies at intermediate transmission distanees; conrersion seale for obtaining optimum working flequeneics.

Nomogram for transforming E-layer 2000-muf to equivalent maximum wsable frequencies and optimum working frequencies due to combined effect of $E$ layer and $F 1$ layel at other transmission distanees

T. Absorption, distanee range, and lowest useful high frequeney ..................... Page 4

Absorption inclex chart (excluding anroral absolption) for September _. _. Fig. 16

VI. Sample muf and owf caleulations_..._._. Page 5

For short paths (under $4000 \mathrm{~km}$ ) page 5 , table 1, page 6, and Fig. 17.

For long paths (over $4000 \mathrm{~km}$ ) page 5 , table 2, page 7 , and Fig. 18.

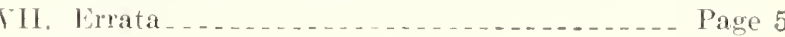




\section{TERMINOLOGY}

The following symbols are used, as recommended by the International Radio Propagation Conference lield in Washington, D. C., 17 April to 5 May 1944.

$$
\begin{array}{r}
f^{\circ} F 2=\text { or dinary-wave critical frequency } \\
\text { for the } F 2 \text { layer. The term } \\
\text { night } F \text { layer will no longer be } \\
\text { used. The term } F 2 \text { layer is } \\
\text { now used for the night } F \text { as } \\
\text { well as the daytime } F 2 \text { layer. } \\
f^{x} F^{\prime}=\text { extraordinary-wave critical fre- } \\
\text { quency for the } F 2 \text { layer. } \\
E, s=\text { soradic, or abnormal } E \text {. }
\end{array}
$$

$f E s=$ highest frequency of $E s$ reflections.

muf or MUF $=$ maximum usable frequency.

owf or $\mathrm{OWF}=$ optimum working frequency.

4000 -muf chart $=$ contour chart of muf for 4000 kilometer paths.

2000-muf chart $=$ contour chart of muf for 2000kilometer paths.

Zero-muf chart= contour chart of vertical-incidence critical frequency, extraordinary wave.

$K=$ absorption index (ratio of actual absorption to absorption at the subsolar point).

Nore. - The designation $F F_{2}$ has been replaced by $F_{2}$.

\section{WORLD.WIDE PREDICTION CHARTS AND THEIR USES}

The charts, figures 5 to 11 , present world-wide predictions of monthly average maximum usable frequencies for September 1945. Conditions may be markedly different on disturbed lays, especially in or near the auroral zones, shown on the map of figme 1. The mothod of prediction is discussed in the TRPL Radio Propagation Handbook, Part 1, War Dept. TM 11-499, Navy Dept. DNC-13-1, p. 52, 53.

Although ionosplere characteristics are roughly similar for locations of equal latitude, there is also a considerable variation with longitude, especially in the case of the $F 2$ layer. This "longitucle effeet" seens to be related to geomagnetic latitude. Attention was first called to this effect in the report" "Radio Propagation Conditions" issued 10 Sept. 1943 ; it was brought into general operational use in the next issue (14 Oct. 1943).

The longitude effect in the $F 2$ layer is taken care of by providing world clarts for three zones, in each of which the ionosphere characteristics are independent of longitude, for practical purposes. These zones are indicated on the world map, figure 1.
Two $F 2$ charts are provided for eacli zone, one of which, the "zero-muf chart," shows the verticalincilence muf, or the critical frequeney for the extraordinary wave, and the other, the "4000muf chart," shows the muf for a transmission distance of $4000 \mathrm{~km}$. Do not confuse the zeromuf charts with the $f^{\circ} \mathrm{F} 2$ charts appearing in the previous IRPL reports "Radio Propagation Conditions." (Values of F2-zero-muf exceed those of $f^{\circ} \mathrm{F} 2$ for the same location and local time by an amount approximately equal to half the gyrofrequency for the location. See IRPL Radio Propagation Handbook, Part 1 (War Dept. TM 11-499 and Navy Dept. DNC-13-1), p. 18, 19. 28, and fig. 9).

The longitude variation is operationally neg ligible in the case of the normal $E$ layer and therefore only one E-layer chart is provided.

The variation of $f E s$ with geomagnetic latitude seems to be well maked and important. Consequently, the $f E s$ charts are constructed on the basis of geomagnetic latitude. Since there are, as yet, insufficient correlated data, the $f$ Es charts are much less precise than the other charts. Instructions for use of these charts appear in section IV, 3 .

\section{DETERMINATION OF GREAT-CIRCLE DISTANCES, BEARINGS, LOCATION OF TRANSMISSION CONTROL POINTS, SOLAR ZENITH ANGLES}

1. The first step in any radio propagation calculation is the determination of the transmission path, which is the great-circle distance between transmitting and receiving stations. Use the world nap, figure 1, and the great-circle chart, figure 2, for this purpose, as follows:

a. Place a piece of transparent paper over the map, figure 1, and draw upon it a convenient reference latitude line, the locations of the transmitting and receiving stations, and the meridian whose local times are to be used as the times for calculation.

b. Place this transparency over the chart, figure 2 , and, keeping the reference line at the proper latitude, slide the transpareney horizontally until the teminal points marked on it either fall on the same great-circle curve, or fall the same proportional distance between adjacent grcat-circle curves. Draw in the path.

c. Locatie the midpoint of the path, for paths under $4000 \mathrm{~km}$, or the "control points," $2000 \mathrm{~km}$ from either end of the path, for paths greater than $4000 \mathrm{~km}$, and use for this purpose the small circles of figure 2.

d. Place the transpareney over the predicted chart at the proper latitude and local time, and read the values of muf off the chart, as directed in section IV. 
2. Great-circle distances, bearings, location of midpoints, or other "control points" $2000 \mathrm{~km}$ in from the ends of the transmission path, as well as solar zenith angles, may be readily obtained from the nomogram, figure 4 .

Referring to the auxiliary diagram, figure 3, let $Z$ and $S$ be the locations of transmitting and receiving stations, where $Z$ is the west, and $S$ the east end of the path. Consider north latitudes+ and south latitudes-, and take the absolute value of any sums or differenees of angles (without regard to sign). Use the nomogram, figure 4, as follows: a. To obtain the great-circle distance ZS:

(1) Draw slant line from (lat. of $Z$-lat. of $S$ ) measured up from bottom of left scale, to (lat. of $Z+$ lat. of $S$ ), measured down from top of right scale.

(2) From the longitude difference between $S$ and $Z$, on bottom seale, measured from left to right, draw vertical line to the slant line obtained in (1). (Use either the longitude difference or $360^{\circ}$ - the longitude difference, whichever is the smaller.)

(3) From the intersection, draw a horizontal line to the left scale. This gives $Z S$ in degrees.

(4) Convert the distance ZS to kilometers, statute miles, or nautical miles, by using the scale at the bottom of figure 4.

b. To obtain the bearing angle PZS:

(1) Subtract the distance $Z S$ (in degrees) from $90^{\circ}$ to get $h$.

(2) Draw slant line from (lat. $Z-h$ ), measured up from bottom on left scale, to (lat. $Z+h$ ), measured down from top on right seale.

(3) From $\left(90^{\circ}\right.$-lat. $\left.S\right)$ on left, measured up from bottom on left scale, draw horizontal line until it intersects previous slant line.

(4) From the intersection, draw a vertical line to the bottom scale, which gives the bearing angle PZS, in degrees.

c. To obtain the bearing angle PSZ:

(1) Repeat steps (1), (2), (3) and (4) in b, interchanging $Z$ and $S$ in all computations. The result obtained is the interior angle PSZ, in degrees.

(2) The bearing angle PSZ is $360^{\circ}$ minus the result obtained in (1) (since bearings are customarily given clockwise from due north).

d. To obtain latitude of Q (mid, or other, pornt of path):

(1) Obtain $Z Q$ in degrees. If $Q$ is the midpoint of the path, $Z Q$ will be equal to one-half ZS. If $Q$ is one of the $2000-\mathrm{km}$ "control points," $Z Q$ will be approximately $18^{\circ}$, or $Z S-18^{\circ}$.

(2) Subtract $Z Q$ from $90^{\circ}$ to get $h^{\prime}$.

(3) Draw slant line from (lat. $Z-h^{\prime}$ ), measured up from bottom of left seale, to (lat. $Z+h^{\prime}$ ), measured down from top on right seale.

(4) From bearing angle $P Z S$, measured to right on bottom scale, draw vertical line to the above slant line.

(5) From this intersection, draw horizontal line to left scale.

(6) Subtract the reading given from $90^{\circ}$ to give latitude of $Q$ in degrees.

e. To obtain longatude difference, $t^{\prime}$, between $Z$ and $Q$;

(1) Draw straight line (lat. Z-lat. Q), measured up fiom bottom on left-hand scale, to (lat. $Z$ that. Q), measured down from top on righthand scale.

(2) From the left side, at $Z Q$, in degrees, draw a horizontal line to the above slant line.

(3) From the intersection, drop a vertical line to bottom seale to g'et $t^{\prime}$ in degrees.

f. To obtain solar zenith angle, $\psi$, at a given place:

(1) Let the declination of the sun be $d$, and let $Z$ be the place under consideration.

(2) Draw straight line from (lat. $Z-d$ ), measured up from bottom on left scale, to (lat. $Z+d$ ), measured down on right scale.

(3) From [(12-local time of $Z$, in hours $) \times 15]$ degrees, on bottom scale, measured from left to right, draw a vertical line to the slant line above.

(4) From this intersection, draw a horizontal line to the left scale. This gives $\psi$, in degrees.

\section{CALCULATION OF MAXIMUM USABLE FREQUENCIES AND OPTIMUM WORKING FREQUENCIES}

\section{PROCEDURE FOR DETERMINATION OF MUF OR OWF FOR TRANSMISSION DISTANCES UNDER 4000 KM}

Radio propagation over distances up to $4000 \mathrm{~km}$ is usually determined by ionospheric conditions at the midpoint of the great-circle path between transmitting and receiving station.

Use the following procedure for obtaining the muf and owf for distances less than $4000 \mathrm{~km}$ :

a. Locate the midpoint of the transmission path. (Methods for doing this are given in the preceding section of this report.)

b. Read the values of F2-zero-muf, F2-4000muf, and E-layer 2000-muf for the midpoint of the path at the local time for this midpoint. Be sure to choose the F2 charts for the geographical zone in which the midpoint lies. (For a path just 4000 km long the $F$-zero-muf need not be read; omit step c below, in this case, since the $F^{2} 2-4000$-muf is the F2-layer path muf.)

c. Place a straightedge between the values of F2-zero-muf and F2-4000-muf at the left- and right-hand sides, respectively, of the grid nomogram, figure 13, and read the value of the muf for the actual path length at the intersection point of the straightedge with the appropriate vertical distance line. (Note that the 4000-muf scale on the grid nomogram is only for frequencies up to $35 \mathrm{Mc}$. To use the nomogram for higher values of F2-4000muf multiply both the zero-muf and the 4000-muf scales by two, and use as instructed above.) 
d. The F2-layer optimum working frequency (owf) is 85 percent of the muf, to allow a nargin of safety for day-to-day variations; to determine the owf, use the auxiliary scale at the right of the grid nomogram of figure 13. (For values of muf greater than 35 Me, multiply the muf and owf scales be two.)

a. Place a straightedge between the value of the E-layer 2000-muf located on the left-hand scale of the nomogram, figure 14, and the value of the path length on the right-hand scale, and read the combined $E$ - and $F$-layer muf or owf for that path length, off the central scale. (The characteristics of the $E$ laver and of the $F$ layer ar'e sufficiently related that, for most pratical purposes, they may be combined in this manner.)

f. Compare the values of nuf or owf obtained by operations $\mathrm{c}$ to $\mathrm{e}$. The higher of the two values thus determined is the muf or owf for the path.

\section{PROCEDURE FOR DETERMINATION OF MUF OR OWF FOR TRANSMISSION DISTANCES GREATER THAN $4000 \mathrm{KM}$}

The complexities of long-distance radio propagation are such that the simple multihop $E^{\prime}$ or $F 2$ layer calculations do not give accurate results. The following procedure will give results which are operationally satisfactory; the theory involved is outside the scope of this report.

i. Locinte the two "control points" $2000 \mathrm{~km}$ from the ends of the great-cincle distance between transmitting and receiving stations. For very long paths both the "short route" (mimor are of the great-circle path) and the "long route" (major are) need to be consiclered.

b. Read the value of the $F 2-4000-m u f$, at the local time for each point, at these points, being sure to choose the appropriate zone for each point. c. Calculate the F2-4000-owf for each point (85 pereent of the muf) by means of the auxiliary muf-owf scale of figure 13. (For values of muf greater than $35 \mathrm{Me}$, multiply the muf and owf scales by two.)

d. Compare these two muf or owf values. The lower of the two is the muf or owf for the transmission path under consideration.

c. When one of the control points lies in a region where the E-2000-muf is greater than the F24000-muf, read the E-2000-muf at an E-layer control point $1000 \mathrm{~km}$ from the end of the path, instead of the F2-4000-muf, as in step b. Use the E-2000-muf in step d, insteal of the $F 2-4000-$ muf or owf.

\section{PROCEDURE FOR DETERMINATION OF ES TRANSMISSION}

\section{(Note Change in Charts and Procedure)}

Sporadic-E (Es) propagation plays an important part in transmission over paths in some parts of the world and at certain times. It may often allow regular transmission at times when regular F'-layer propagation would not. Es data are not yet sufficient to permit accurate calculations of such propagation, but the $f E s$ charts of figures 12 and 15 are given as a guide to Es occurrence.

Since the fEs charts are constructed from considerations of geomagnetic latitude, three latitude scales are provided at the right of the charts of figures 12 and 15 , one for each of the three zones of figure 1 ( $\mathrm{H}^{-}, l$, and $E$ ).

Until improvements are made the following procedure should be used to find the prevalence of Es propagation over a transmission path.

a. For paths over $4000 \mathrm{~km}$ long:
(1) Place the great-circle path transparency prepared in section III, 1 , over the median fEs chart, figme 12 , using the latitude scale for the zone containing the control point.

(2) Scale fEs at each E-layer control point (1000 knu from either end of the path), multiply by 5 and subtract 4 Me. The result is the Es-owf

(3) Plot as the owf for anch control point the highest of the three values; the $F 2$-4000-owf, the E-2000-owf, and the Es-owf.

b. For paths less than $4000 \mathrm{~km}$ long, scale the fEs at the midpoint of the path, using the latitude scale for the appropriate zone, multiply by 5 and subtract 4 Me, and use the resultant frequency as outlined above for the E-layer $2000-$ muf in the nomogram of figure 14. The result is the Es-owf.

\section{ABSORPTION, DISTANCE RANGE, AND LOWEST USEFUL HIGH FREQUENCY}

The determination of absorption, distance range, and lowest useful high frecuency is discussed at length in IRPL Radio Propagation Handbook, Part 3, p. 69-97 (War Dept, TM 11-499, Navy Dept. DNC $-13-1$ ), and formulas, graphs, and nomograns for calculation ale given there, For convenience in estimating absorption (exclusive of auroral absorption) orer a path, the ahsorption index $\left(0 K^{\circ}\right)$ chat, figure 16 , is presented. By superpesing on this whart the transpareney with the great-circle path, prepared as in section III, 1 , the relation of the path to the sun's zenith angle is readily seen (the sumrise-sunset line corresponds to all absorption index approxinately $=0.14$ ).

The absorption is erratic and considerably greater in and near the auroral zones, shown on the map of figure 1 ; paths passing through or near these zones are subject at times to severe disturbances. 


\section{SAMPLE MUF AND OWF CALCULATIONS}

\section{FOR SHORT PATHS}

Required: The muf and owf for transmission between Washington, D. C. $\left(39.0^{\circ} \mathrm{N}, 77.5^{\circ} \mathrm{W}\right)$ and Miami, Fla. $\left(25.7^{\circ} \mathrm{N}, 80.5^{\circ} \mathrm{W}\right)$ for average conditions during the month of Septenber 1945.

\section{Solution:}

Let the local time used for this problem be GCT (Z time or that of $0^{\circ}$ longitude).

The midpoint of the path is at approximately $32.5^{\circ} \mathrm{N}, 79.0^{\circ} \mathrm{W}$, and the transmission path length is approximately $1500 \mathrm{~km}$.

The values of $E$ - and $F 2$-layer muf and owf, and also Es-owf for alternate hours, GCT, as determined by using the procedure given in section IV, are given in table 1 . The final values are presented graphically in figure 17. In obtaining the combined muf for all layers, the Es-onvf is used because of the great variability of the muf.

Figure 17 shows that skip will occur, on the average, during the night hours, if a frequency as high as 8.0 Me is used. I frequency as high as
6.0 Mc will not skip, on the arerage, a any time of day, but its use is not arlvisable because of (a) the day-to-day variability, causing some probability of skip during the night hours, and (b) ionospheric absorption during the daytime, which is more pronounced at low frequencies.

A satisfactory frequency plan to insure contiumous transmission at all times, over a path hice this, involves the use of two fiequencies, one for night and one for day. Figure 17 shows that a night flequency of $5.1 \mathrm{Mc}$, to be used from 2340 to 1245 GCT, and a day frequency of $11.0 \mathrm{Mc}$, to be used from 1245 to 2340 GCT, would be satisfactory. The periods of usefulness of these frequencies are shown by the heavy dashed line on figure 17.

Periods of time during which transmission is controlled by either the $E$ laye or the $F 2$ layer may be easily recognized by noting the relative proximity of the muf and owf curves of figure 17. Coincidence of the curves indicates control by sporadic-E reflections.

\section{FOR LONG PATHS}

Required: The muf and owf for transmission between Naha, Okinawa $\left(26.1^{\circ} \mathrm{N}, 127.8^{\circ} \mathrm{E}\right)$, and San Francisco, Calif. $\left(37.8^{\circ} \mathrm{N}, 122.4^{\circ} \mathrm{W}\right)$, for average conditions during the month of September 1945 .

\section{Solution:}

Let the local time for this problem be GCT ( $Z$ time $0^{\circ}$ that of $0^{\circ}$ longitude).

The path length is approximately $9,900 \mathrm{~km}$, and the two F2-layer control points, $A$ and $B$, respectively, are at approximately $45^{\circ} \mathrm{N}, 143^{\circ} \mathrm{W}$, and $32^{\circ} \mathrm{N}, 143^{\circ} \mathrm{E}$. These are, respectively, in the $I$ zone and the $E$ zone, as shown on the map, figure 1. The two E-layer and Es-control points, $A^{\prime}$ and $B^{\prime}$, respectively, are located at $42.5^{\circ} \mathrm{N}$, $132^{\circ} \mathrm{W}$, and $32^{\circ} \mathrm{N}, 137^{\circ} \mathrm{E}$. The bearing of San Francisco from Naha is approximately $48^{\circ}$, and of Naha from San Francisco, approximately $302^{\circ}$, both determined by means of the nomogram of figure 4.

The values of muf and owf orer this transmission path, as determined by using the procedure of section IV, are given in table 2 for alt crnate hours, GCT. The final values are shown graphically in fignure 18.

Figure 18 shows that skip will occur, on the average, during the night hours if a frequeney as ligh as $12.0 \mathrm{Mc}$ is used, although higher frequencies may be used during a limited portion of the day.

A good practical arrangement to insure continuous transmission at all times is to select thrce frequencies, in a manner similan to that suggested in the preceding problem. A frequency of $8.6 \mathrm{Me}$ may be used from 0705 to 1950 GCT; a frequeney of $17.0 \mathrm{Me}$ may be used from 2150 to $0350 \mathrm{GCT}$; and a transition frequency of $11.0 \mathrm{Mc}$ may be used from 0350 to 0705 , and from 1950 to $2150 \mathrm{GCT}$.

Relative ploximity of the muf and owf curves of figme 18 indicates that neither Es nor regular E-layel controls transmission at any time.

By inspection of the absorption chart, figure 16 , and the noise map (fig. 119 of the IRPI Radio Propagation Handbook, Part 1, War Dept. TMI 11-499, Navy Dept. DNC-13-1), it may be seen that considerations of the lowest useful high frequency over this path may be of considerable importance in selecting frequencies for use. Consequently, in cases of transmission failure on the frequencies here recommended, particularly in the case of the transition frequeney, changing the frequency to a value slightly under the muf for the path inay be advisable.

\section{ERRATA}

In the previous issue of this report, IRPL-D9 (War Dept. TB 11-499-9, Navy Dept. DNC13-1 (11):

1. The $\mathrm{E}$ and $\mathrm{W}$ latitude scales of figure 15 were interchanged. The scale marked $\mathrm{W}$ shoukd be $\mathrm{E}$ and that marked E should be W.
2. On p. 5, section VT, 2, second paragraph of "Solution," third sentence should read: "The two E-layer and Es-control points $L^{\prime}$ and $B^{\prime}$, l'espectively, are located at $37.5^{\circ} \mathrm{N}, 127^{\circ} \mathrm{E}$, and $433^{\circ}$ $\mathrm{N}, 133^{\circ} \mathrm{W} . "$ 
TABLE 1.--Solution of short-path transmission problem

[Washington, D. C., to Miami, Fla., September 1945]

\begin{tabular}{|c|c|c|c|c|c|c|c|c|c|c|c|c|}
\hline Time, GCT & $\begin{array}{c}\text { E-layer- } \\
2000 \text { - } \\
\text { nufl }\end{array}$ & $\begin{array}{l}\text { Com- } \\
\text { hined } \\
\text { E-and } \\
\text { F1-lay- } \\
\text { er-1500- } \\
\text { muf }\end{array}$ & $\begin{array}{l}\text { Com- } \\
\text { bined } \\
E \text {-and } \\
F 1 \text {-lay- } \\
\text { er-1500- } \\
\text { Owf }\end{array}$ & $\begin{array}{l}\text { Median } \\
\quad f E s\end{array}$ & $\begin{array}{c}E s-2000- \\
\text { owf }\end{array}$ & $\begin{array}{c}E s-1500- \\
\text { Owf }\end{array}$ & $\begin{array}{c}F 2 . \\
\text { layer. } \\
\text { zero- } \\
\text { muf, } \\
\text { II" } \\
\text { zone }\end{array}$ & $\begin{array}{c}\text { F2- } \\
\text { layer- } \\
\text { 4000- } \\
\text { muf, } \\
\text { II' } \\
\text { zolle }\end{array}$ & $\begin{array}{c}F 2- \\
\text { layer- } \\
1500- \\
\text { mu1f }\end{array}$ & $\begin{array}{l}F 2- \\
\text { layer- } \\
1500- \\
\text { owf }\end{array}$ & $\begin{array}{l}\text { Corn- } \\
\text { bined } \\
\text { muf, } \\
\text { all } \\
\text { layers }\end{array}$ & $\begin{array}{l}\text { Com- } \\
\text { bined } \\
\text { owf, } \\
\text { all } \\
\text { layers }\end{array}$ \\
\hline $\begin{array}{l}00 \ldots \ldots \\
02 \ldots \\
04 \ldots \\
06 \ldots\end{array}$ & \begin{tabular}{c}
$M c$ \\
$\cdots$ \\
\hdashline- \\
\hdashline$\cdots$ \\
$\cdots$
\end{tabular} & $\begin{array}{l}M c \\
\cdots- \\
\cdots \\
\cdots-\end{array}$ & $\begin{array}{l}M c \\
\cdots \\
\cdots \\
\ldots\end{array}$ & $\begin{array}{l}\text { Mc } \\
2.4 \\
2.3 \\
2.2 \\
.\end{array}$ & $\begin{array}{l}M c \\
8.0 \\
7.5 \\
7.0 \\
-.-\end{array}$ & $\begin{array}{l}M c \\
7.3 \\
6.8 \\
6.4 \\
-\ldots .--\end{array}$ & $\begin{array}{l}M c \\
6.8 \\
4.9 \\
4.2 \\
4.0\end{array}$ & $\begin{array}{c}M_{c} \\
21.0 \\
13.8 \\
11.5 \\
11.1\end{array}$ & $\begin{array}{r}.1 c \\
12.5 \\
8.4 \\
7.1 \\
6.5\end{array}$ & $\begin{array}{r}Y c \\
10.6 \\
7.1 \\
6.0 \\
5.8\end{array}$ & $\begin{array}{r}\text { Wc } \\
12.5 \\
\text { 8. } 1 \\
7.1 \\
6.8\end{array}$ & $\begin{array}{r}M c \\
10.6 \\
7.1 \\
6.4 \\
5.8\end{array}$ \\
\hline $\begin{array}{l}0 \delta_{\ldots} \ldots \ldots \\
10 \ldots \ldots \\
12 \ldots \ldots \\
14 \ldots \ldots\end{array}$ & 10.3 & $\begin{array}{r}9.4 \\
13.6\end{array}$ & $\begin{array}{r}9.1 \\
13.1\end{array}$ & $\begin{array}{l}2.1 \\
2.3\end{array}$ & $\begin{array}{l}6.5 \\
7.5\end{array}$ & 6.0 & $\begin{array}{l}3.7 \\
3.4 \\
5.4 \\
6.7\end{array}$ & $\begin{array}{r}11.1 \\
9.8 \\
16.9 \\
21.6\end{array}$ & $\begin{array}{r}6.6 \\
6.0 \\
10.0 \\
12.6\end{array}$ & $\begin{array}{r}5.6 \\
5.1 \\
8.5 \\
10.7\end{array}$ & $\begin{array}{r}6.6 \\
6.0 \\
10.0 \\
13.6\end{array}$ & $\begin{array}{r}5.6 \\
5.1 \\
9.1 \\
13.1\end{array}$ \\
\hline $\begin{array}{l}16 \ldots \ldots \\
18 \ldots \\
20 \ldots \ldots \\
22 \ldots \ldots\end{array}$ & $\begin{array}{l}16.6 \\
16.7 \\
15.7 \\
12.0\end{array}$ & $\begin{array}{l}15.1 \\
15.2 \\
14.3 \\
11.0\end{array}$ & $\begin{array}{l}14.8 \\
14.9 \\
14.0 \\
10.6\end{array}$ & $\begin{array}{l}\text { 3. } 0 \\
\text { 3. } 1 \\
\text { 3. } 1 \\
\text { 2. } 9\end{array}$ & $\begin{array}{l}11.0 \\
11.5 \\
11.5 \\
10.5\end{array}$ & $\begin{array}{r}10.0 \\
10.5 \\
10.5 \\
9.6\end{array}$ & $\begin{array}{l}7.1 \\
7.5 \\
8.0 \\
7.9\end{array}$ & $\begin{array}{l}21.4 \\
22.1 \\
24.6 \\
25.5\end{array}$ & $\begin{array}{l}12.8 \\
13.3 \\
14.6 \\
14.9\end{array}$ & $\begin{array}{l}10.8 \\
11.3 \\
12.3 \\
12.7\end{array}$ & $\begin{array}{l}15.1 \\
15.2 \\
14.6 \\
14.9\end{array}$ & $\begin{array}{l}14.8 \\
14.9 \\
14.0 \\
12.7\end{array}$ \\
\hline
\end{tabular}

TABLE 2.- Solution of long-path transmission problem.

[Naha, Okinawa Island, to San Francisco, Calif, Septemher 1945]

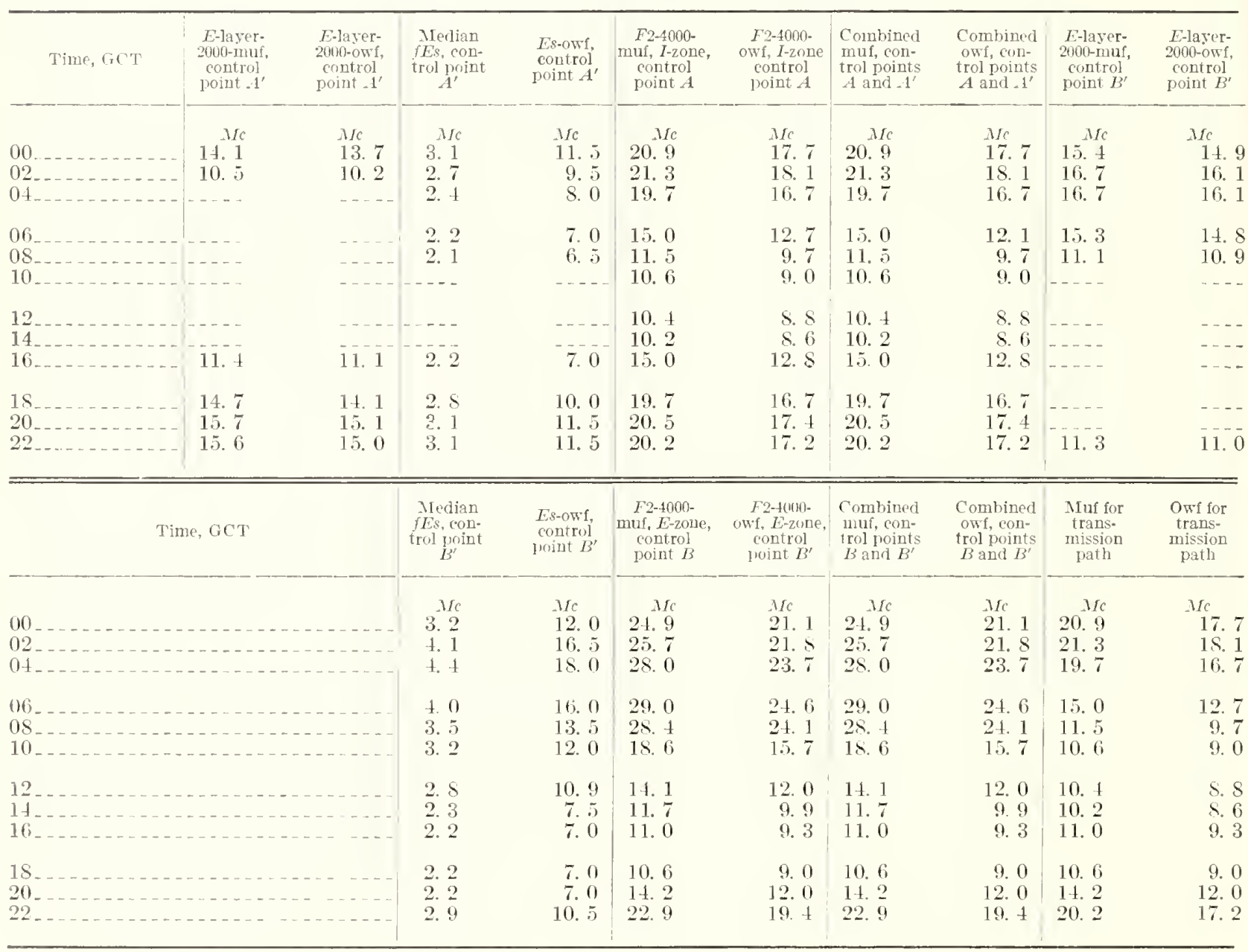





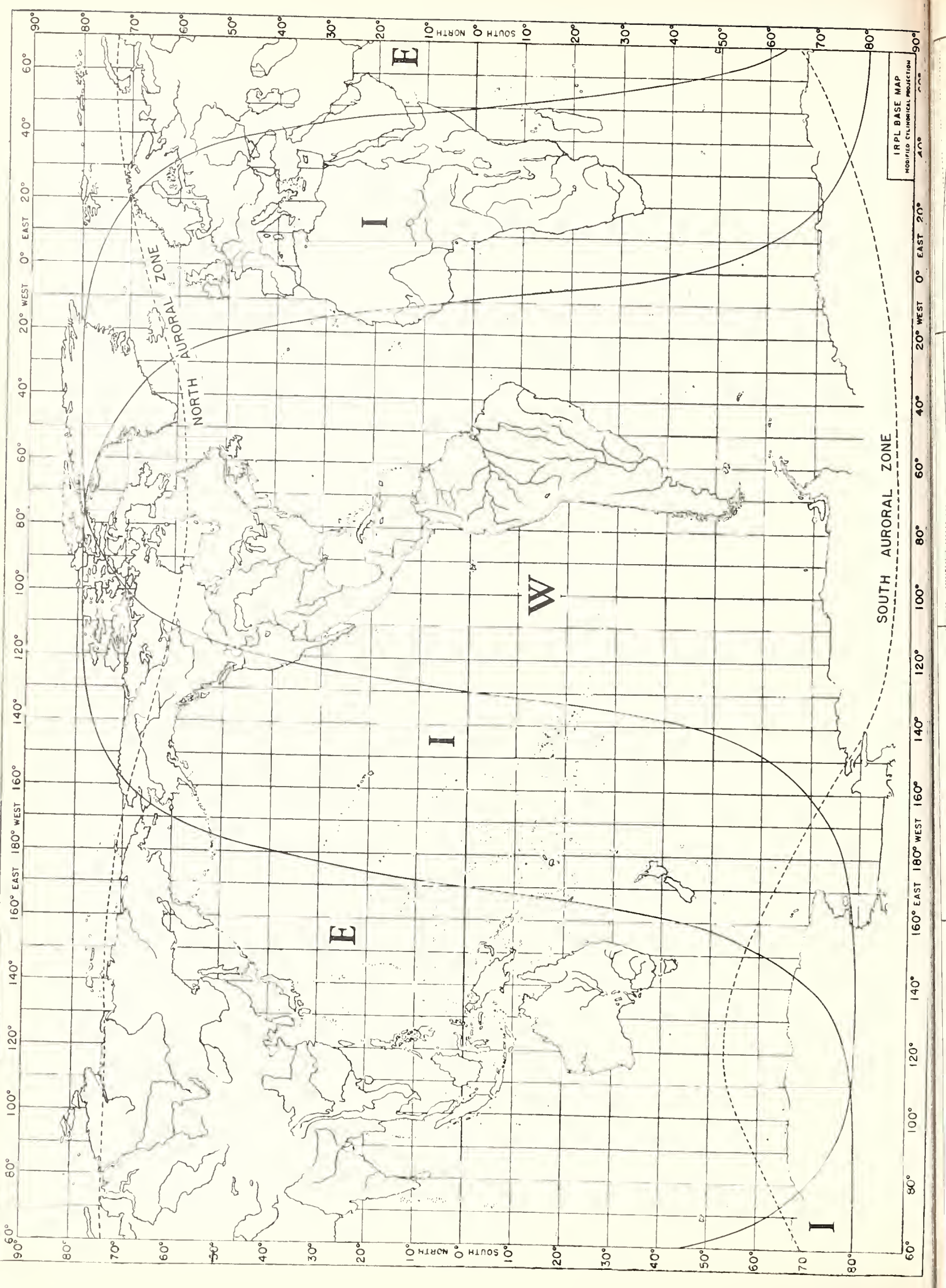




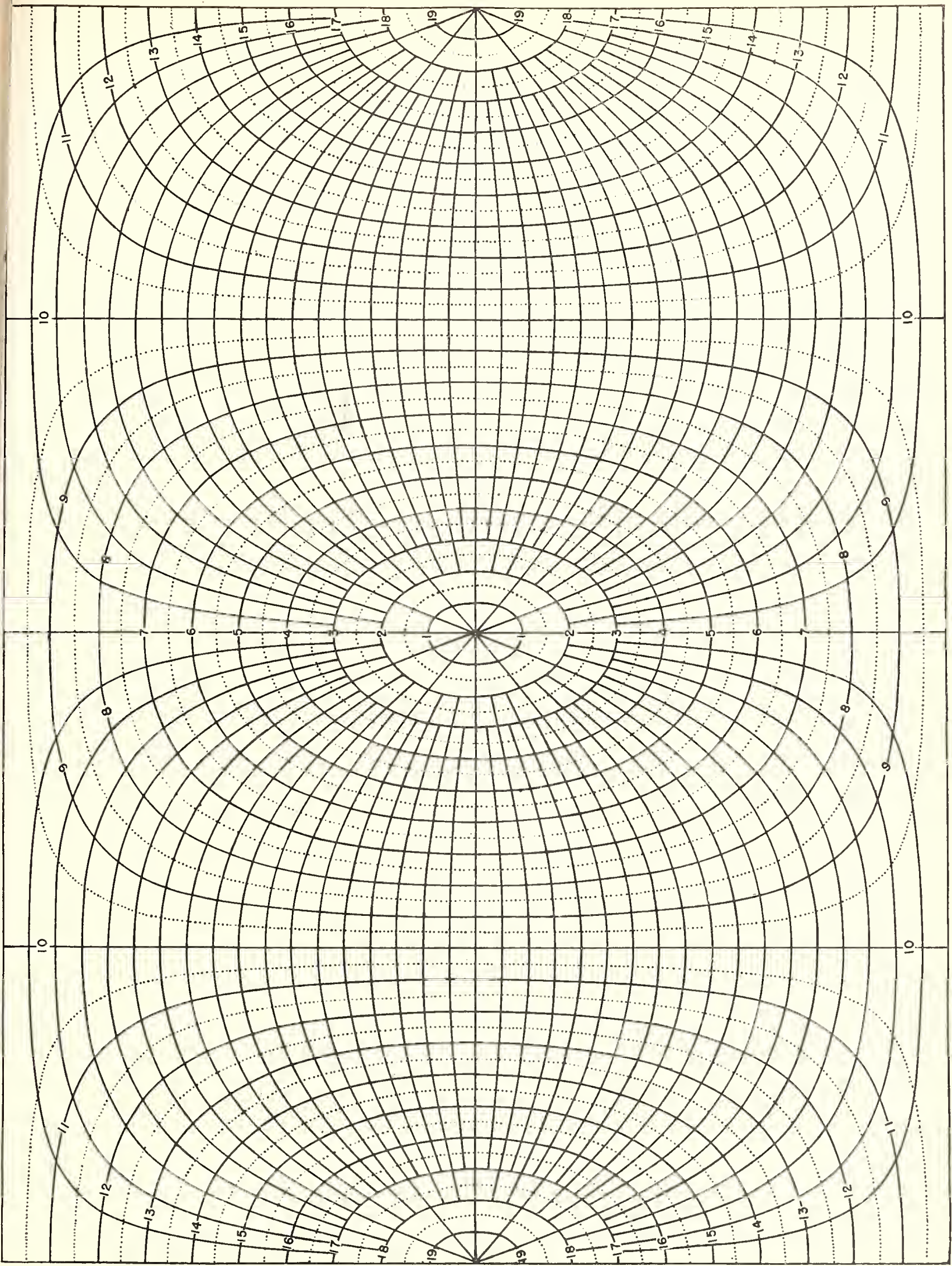

FIG. 2. GREAT CIRCLE CHART, CENTERED ON EQUATOR, WITH SMALL CIRCLES INDICATING DISTANCES IN KILOMETERS. 


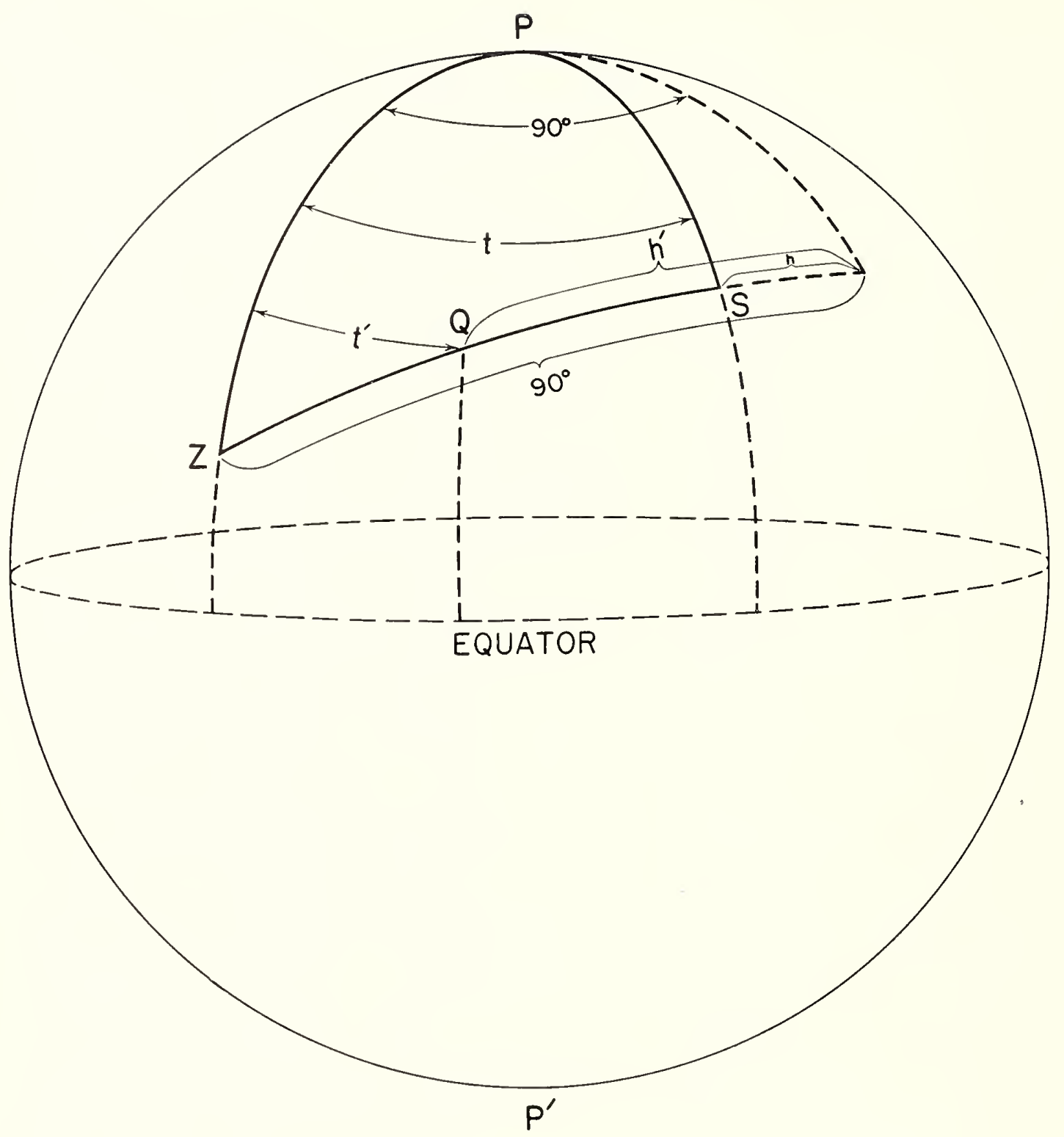

9. 3. DIAGRAM OF TRANSMISSION PATH AUXILIARY TO EXPLANATION OF USE OF DISTANCE - BEARING NOMOGRAM, FIG. 4. 


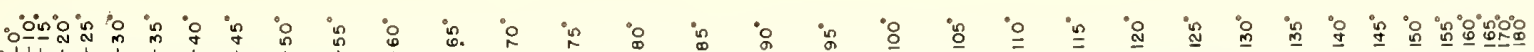

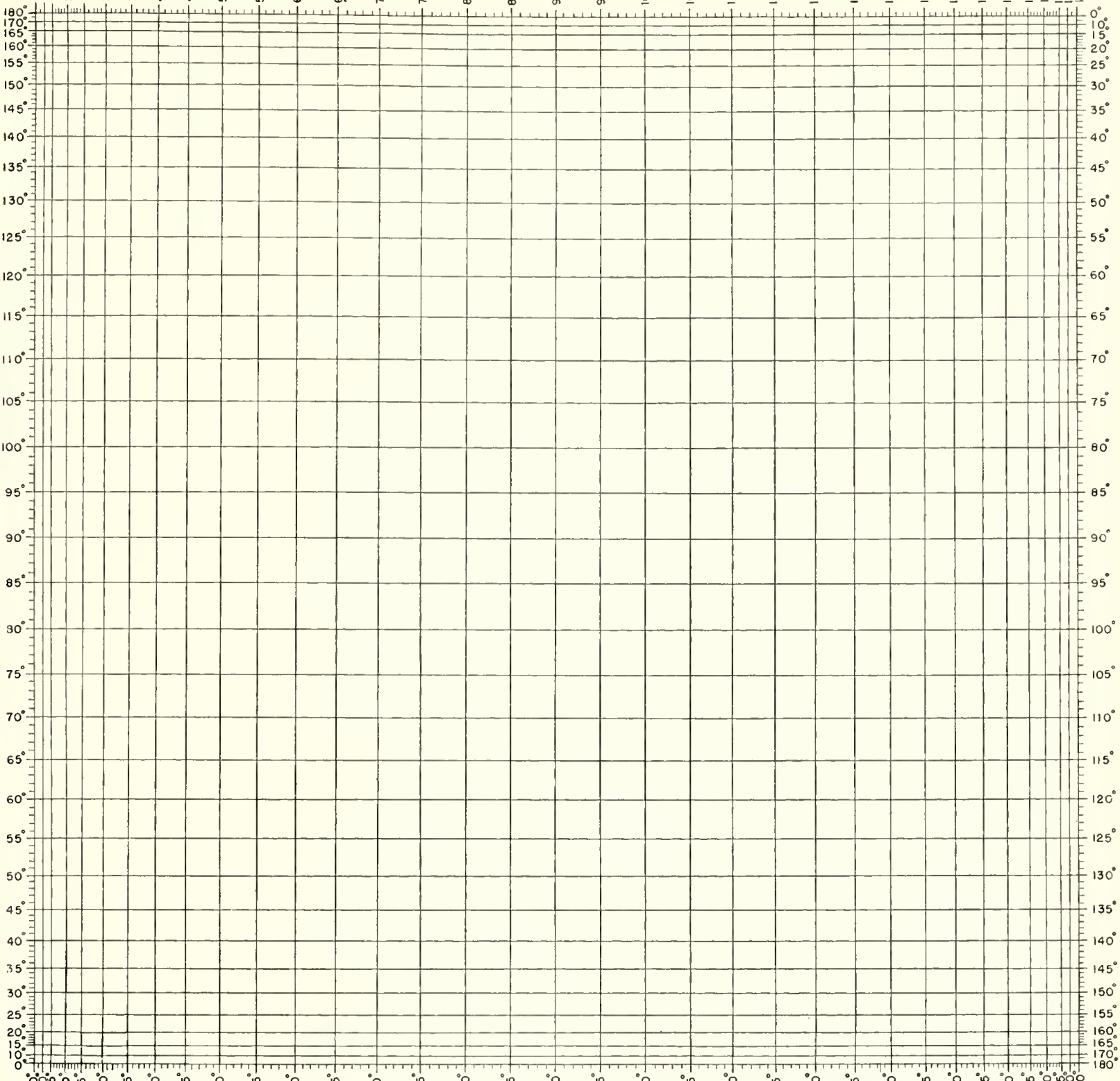

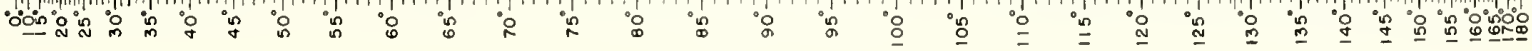

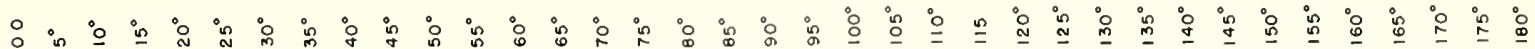

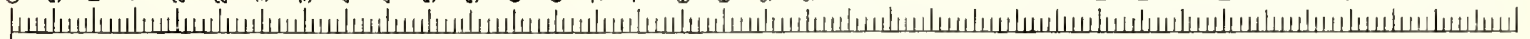
Thousands or Kilometers $^{2}$

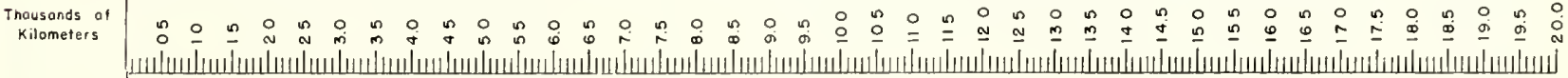

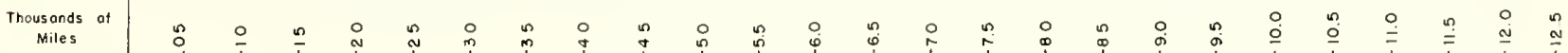

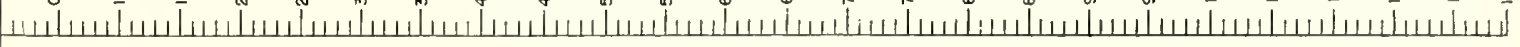

Thousands of
Nautical Miles

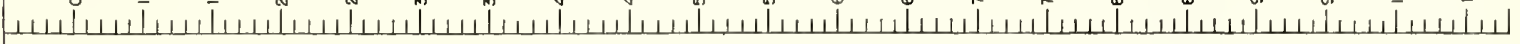

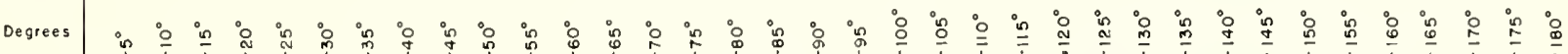
لس لس

Fig. 4. NOMOGRAM (AFTER D'OCAGNE) FOR OBTAINING GREAT-CIRCLE DISTANCES, BEARINGS, LATITUDE AND LONGITUDE OF TRANSMISSION CONTROL POINTS, SOLAR ZENITH ANGLES. CONVERSION SCALE FOR VARIOUS DISTANCE UNITS. 


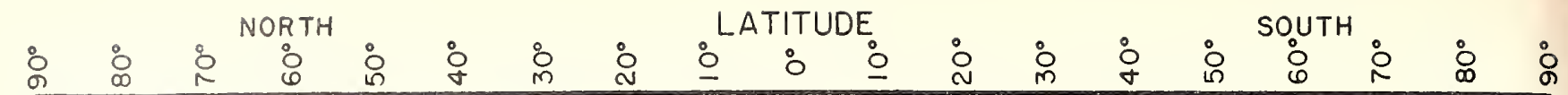
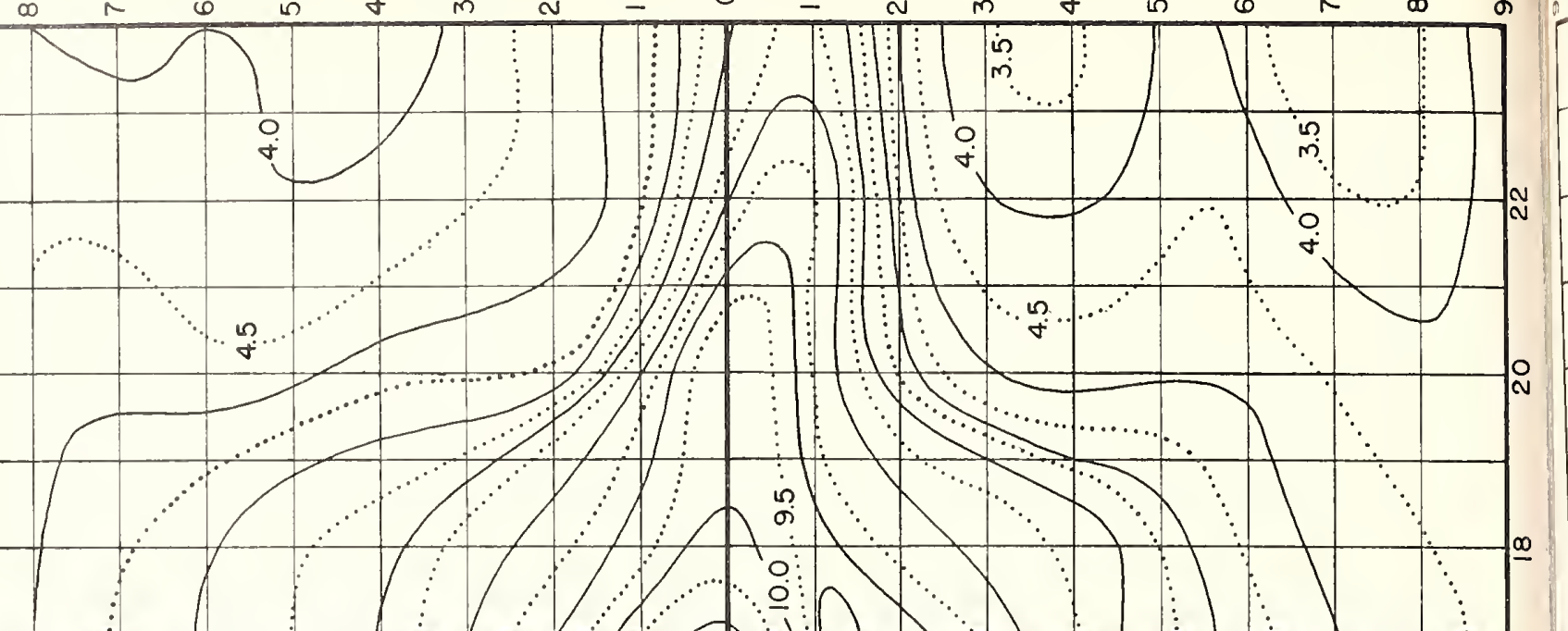

in $\because$

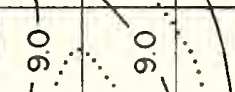

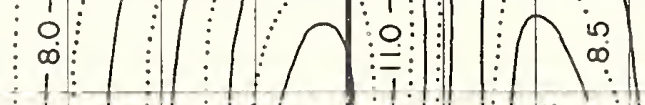

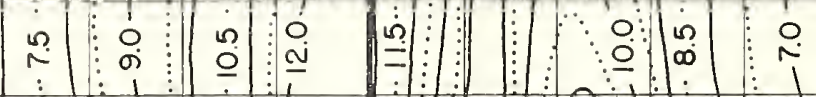

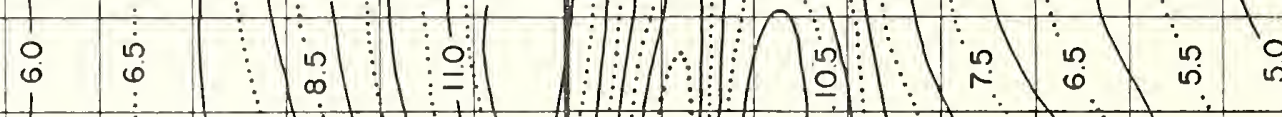

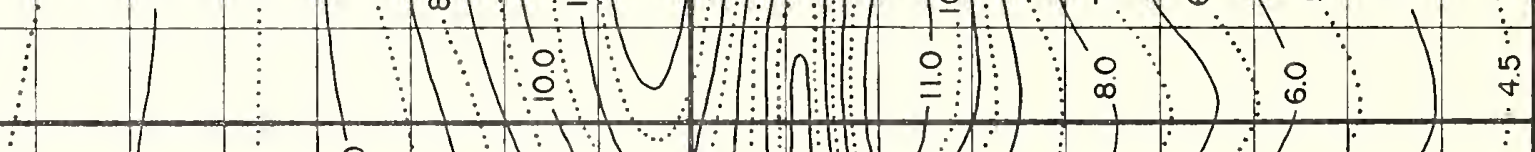

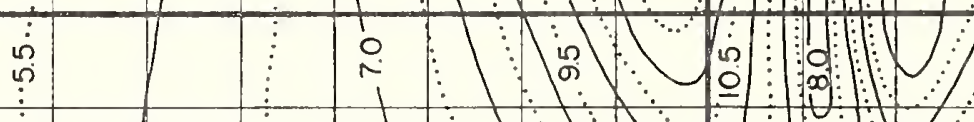
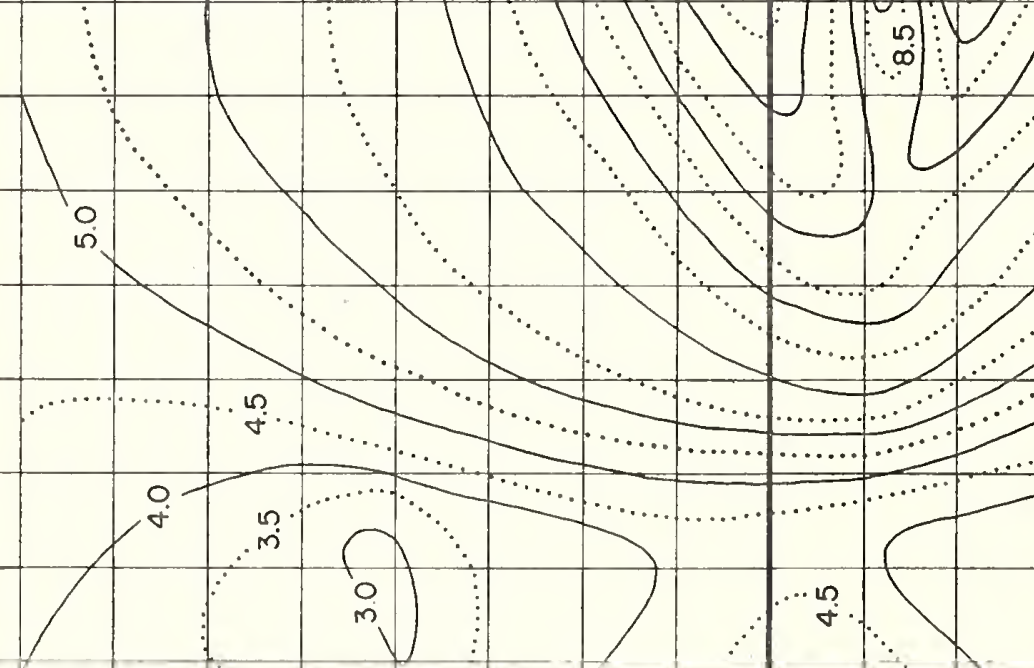


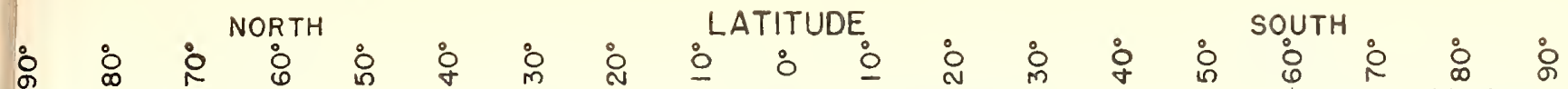

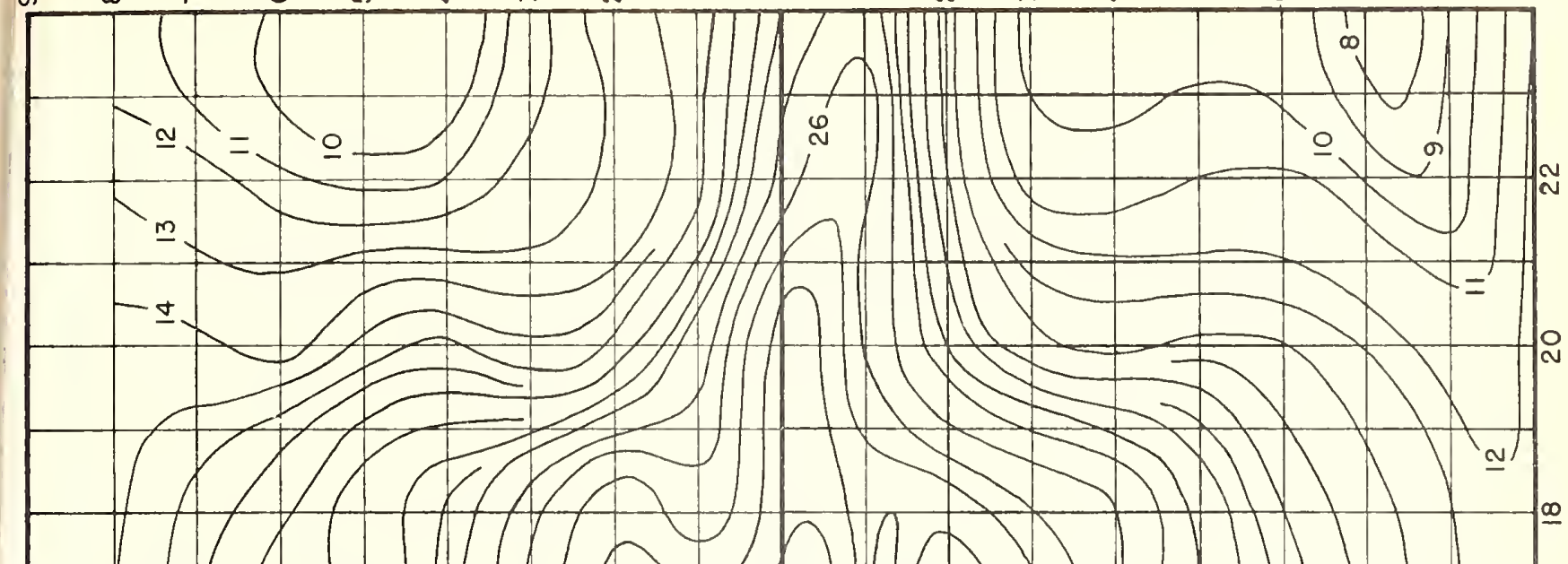

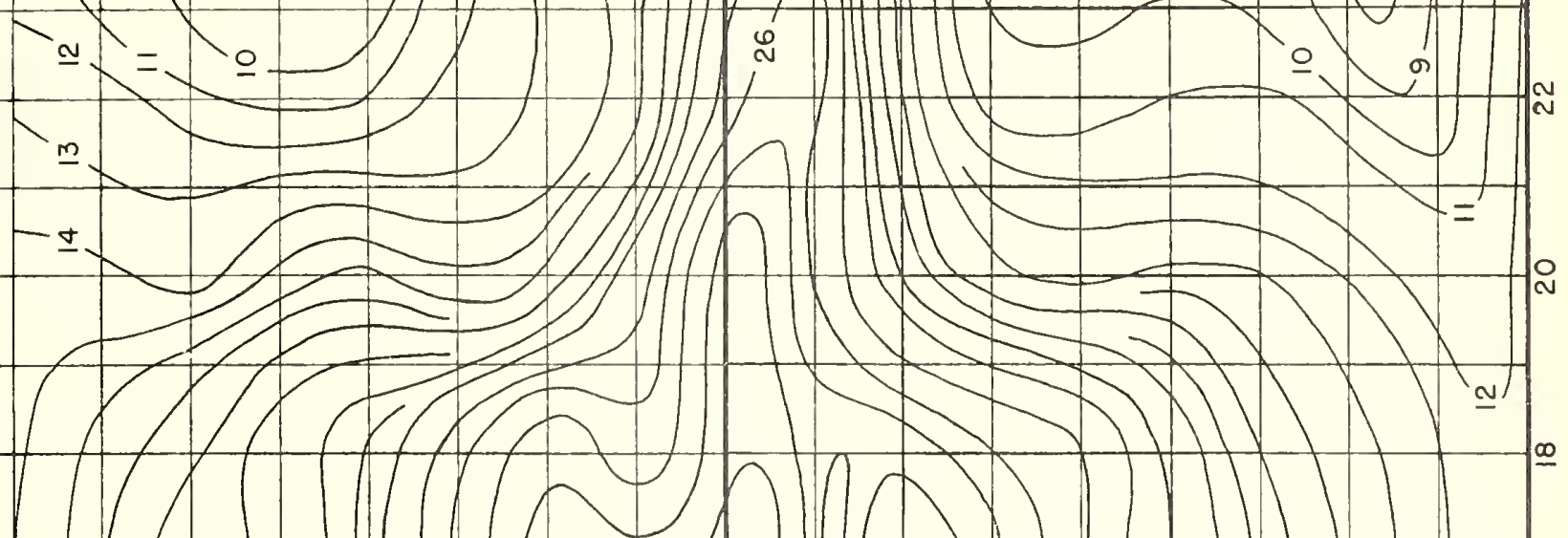

-

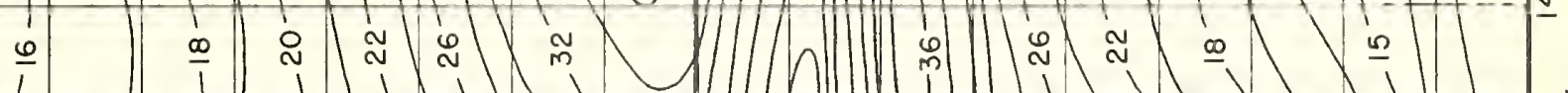

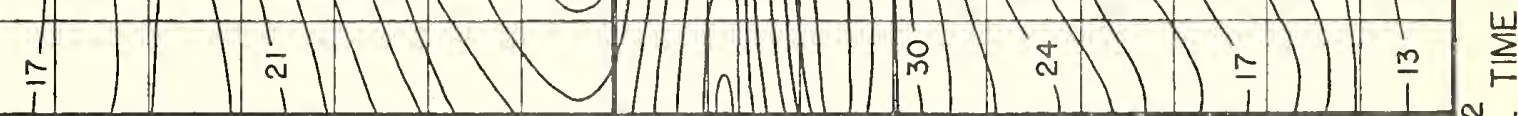

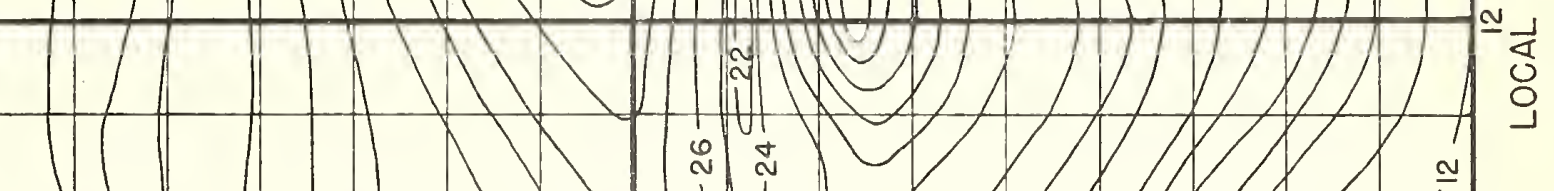

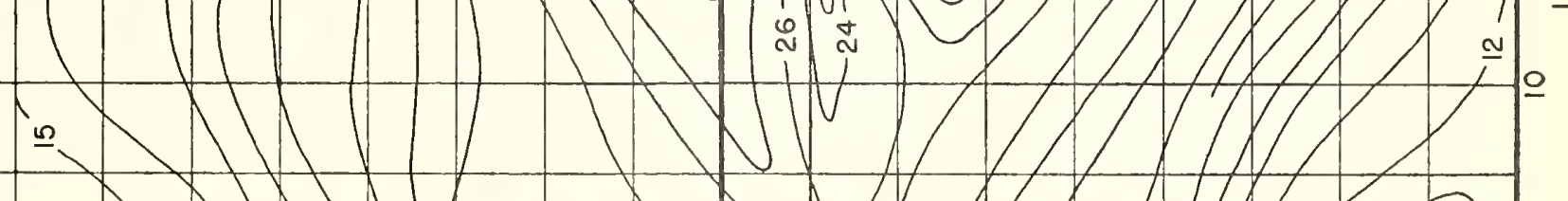
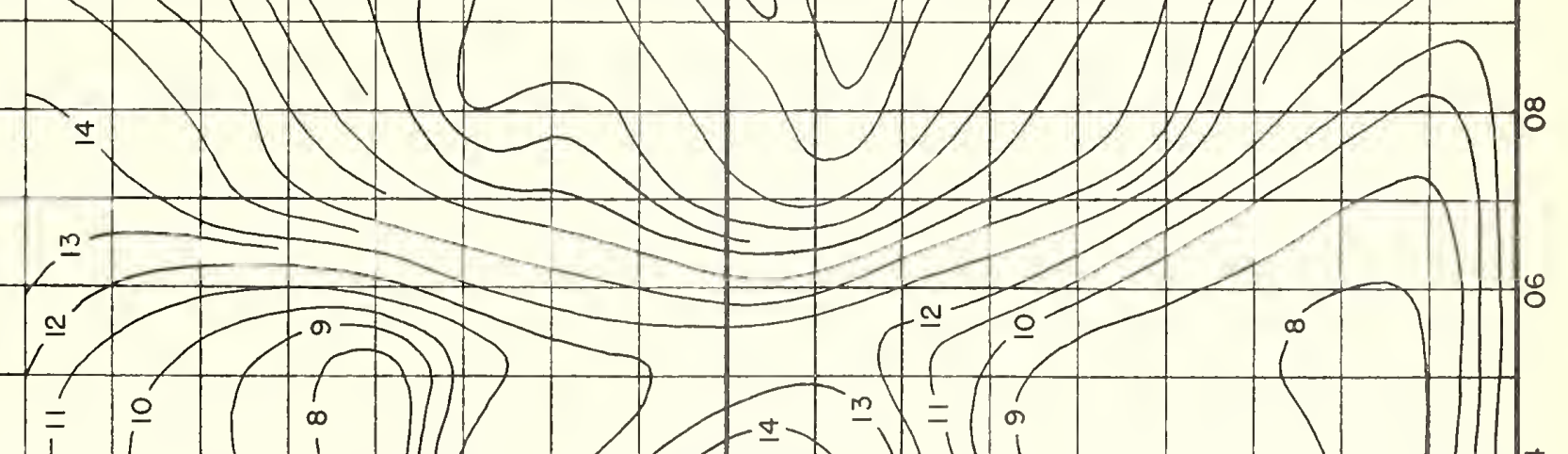

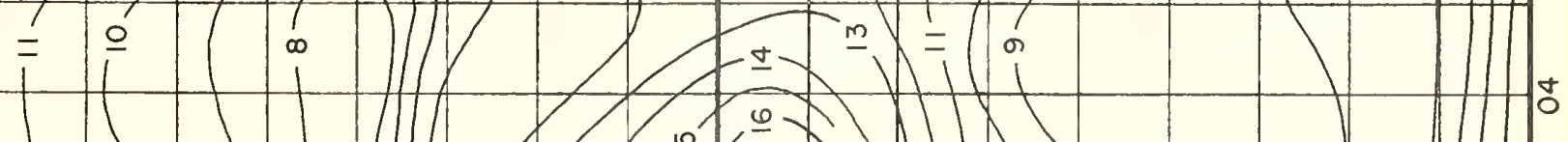

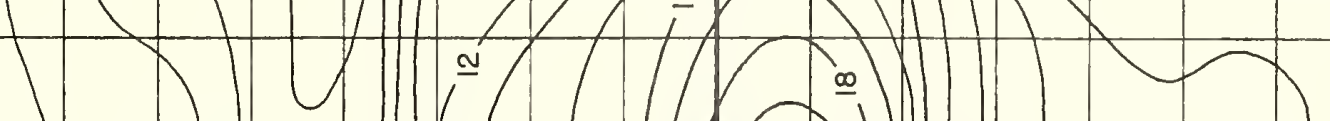

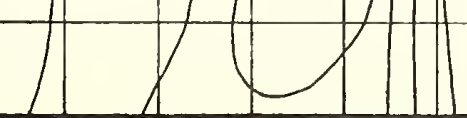

Fig. 6

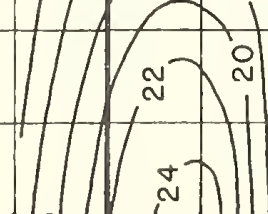

24000-MUF, IN Mc, W ZONE, PREDICTED FOR SEPTEMBER, 1945. 


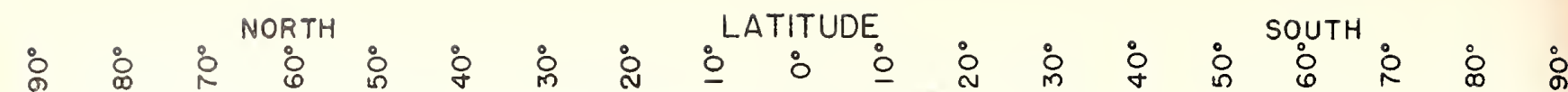

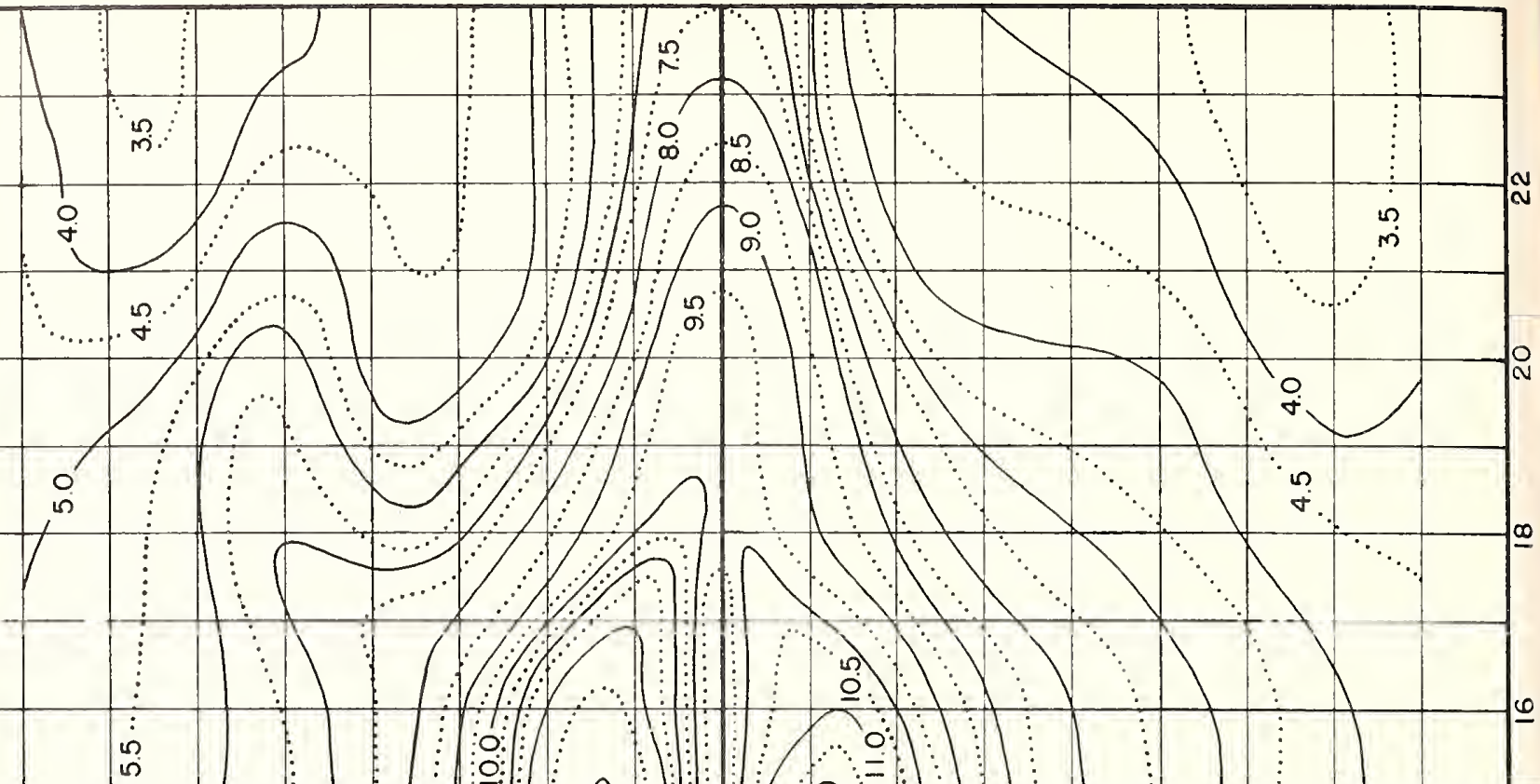

:

$\because$ :

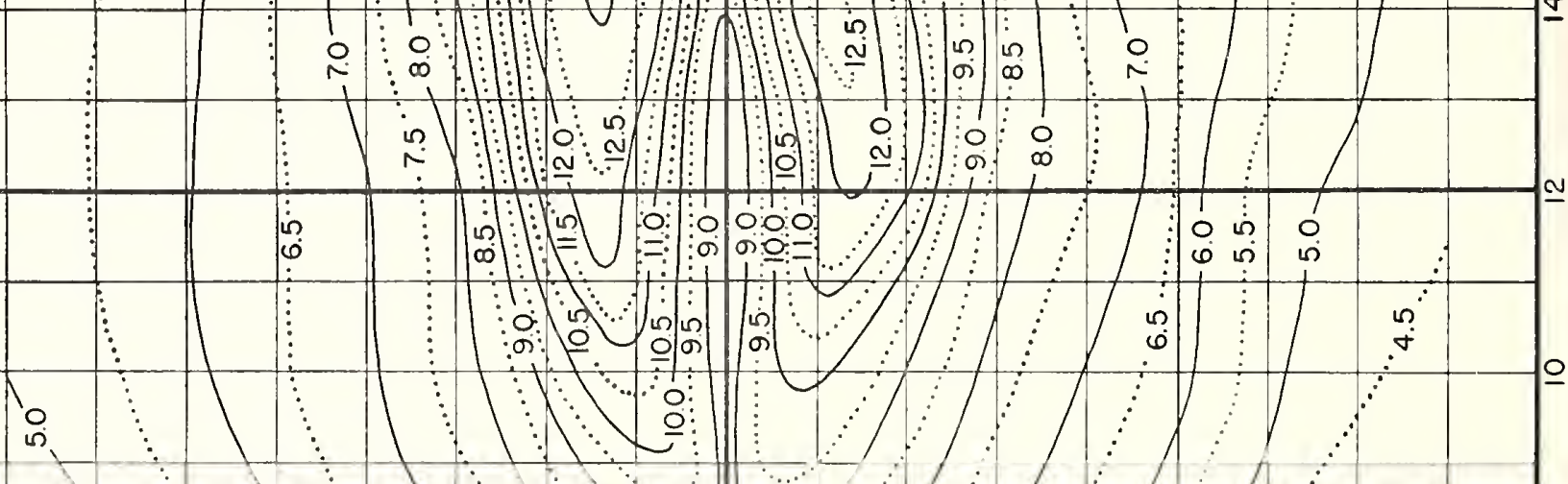

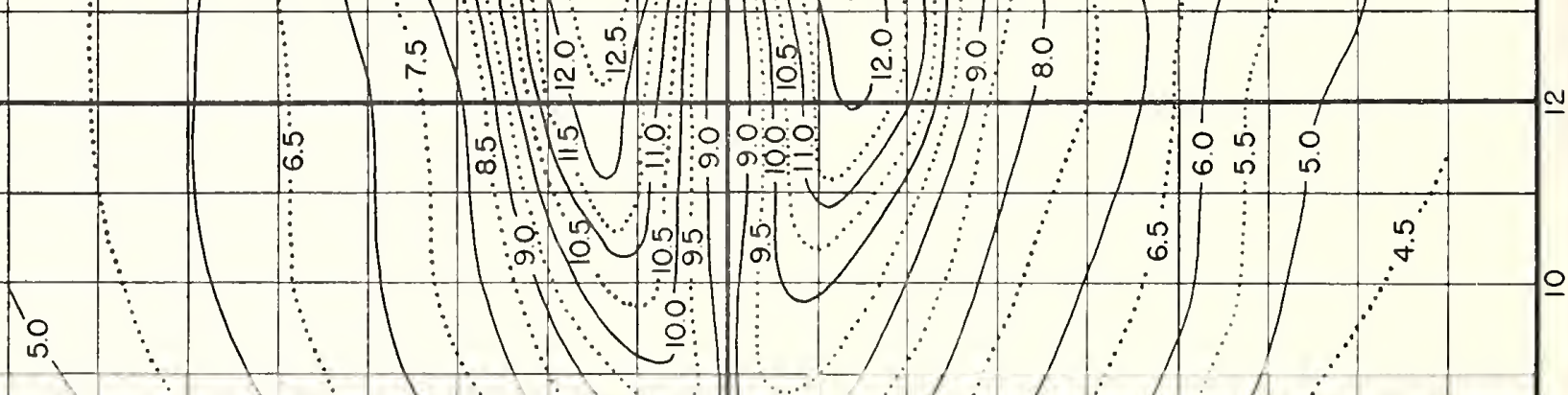

(2)

$\pm$

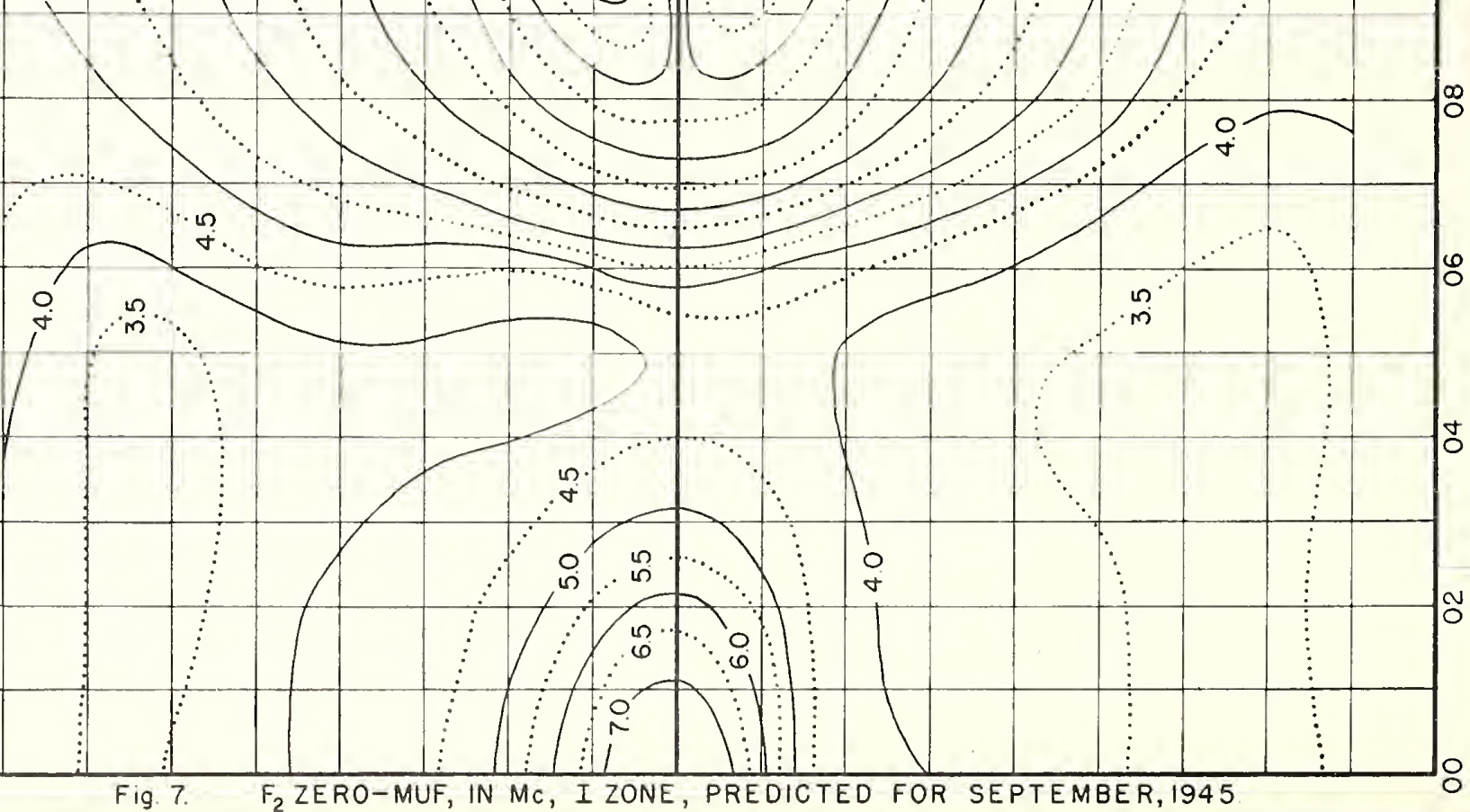




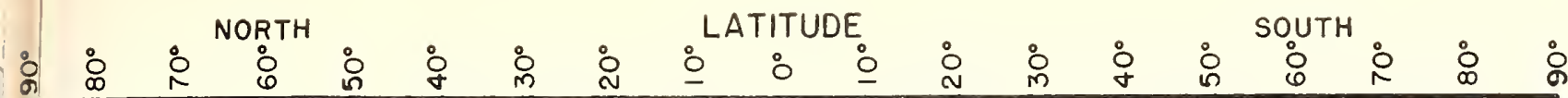
$\stackrel{\circ}{=}$

in -

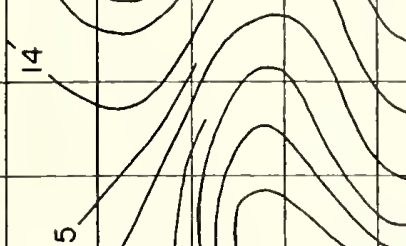

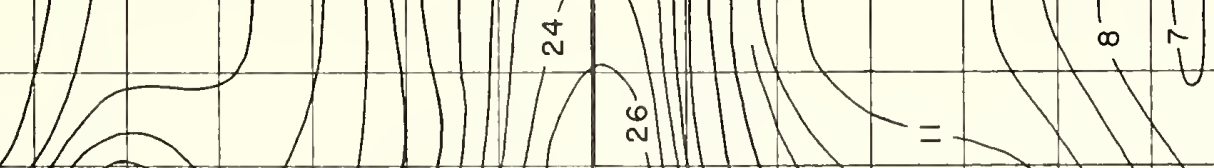




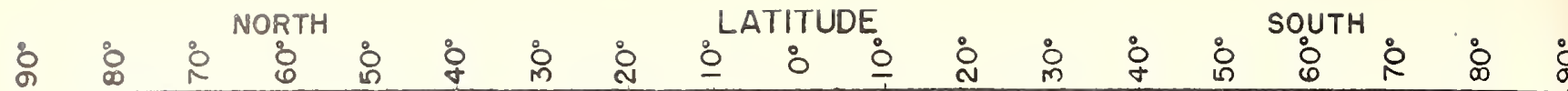
i

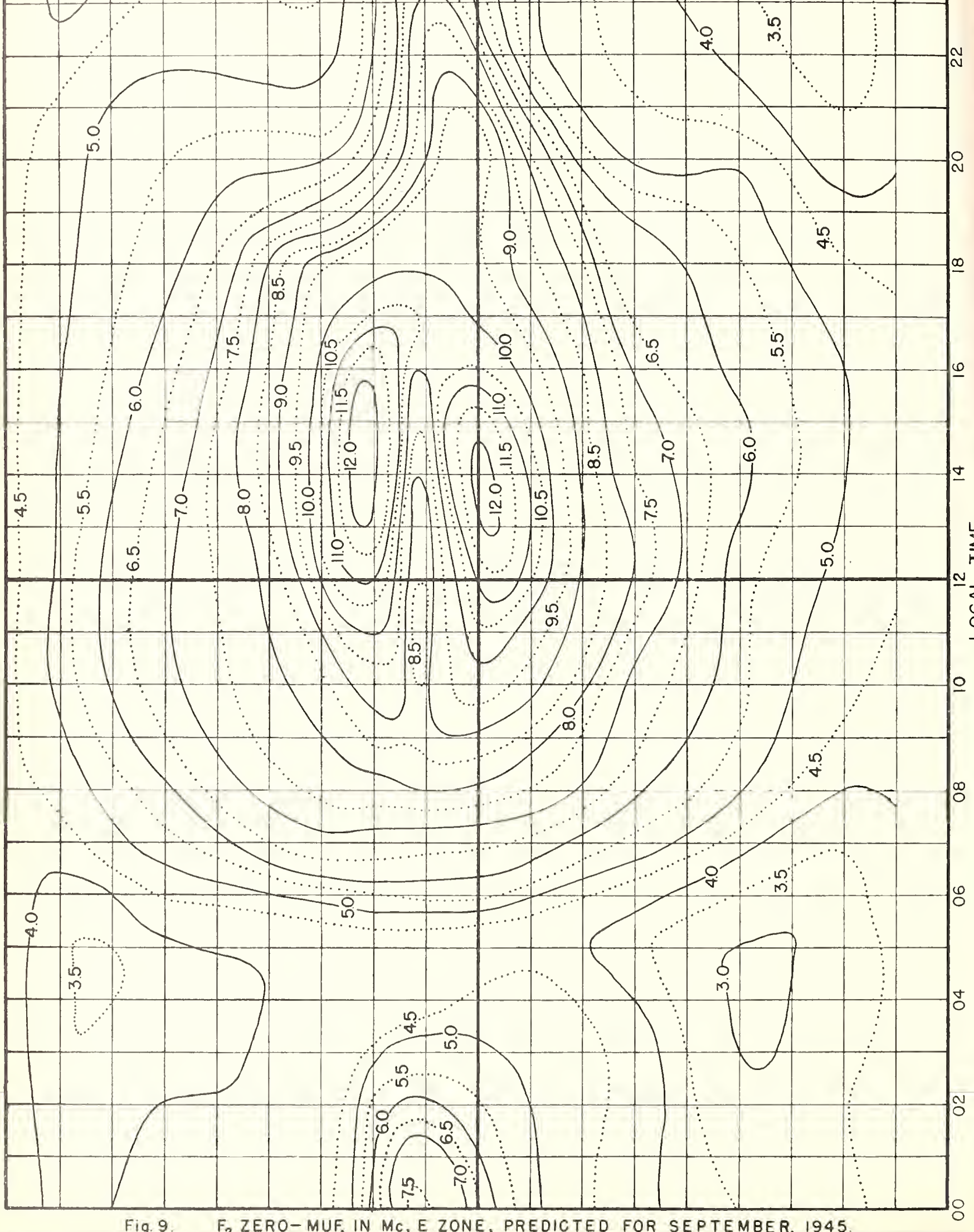




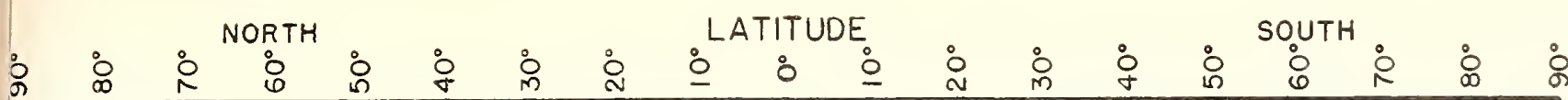

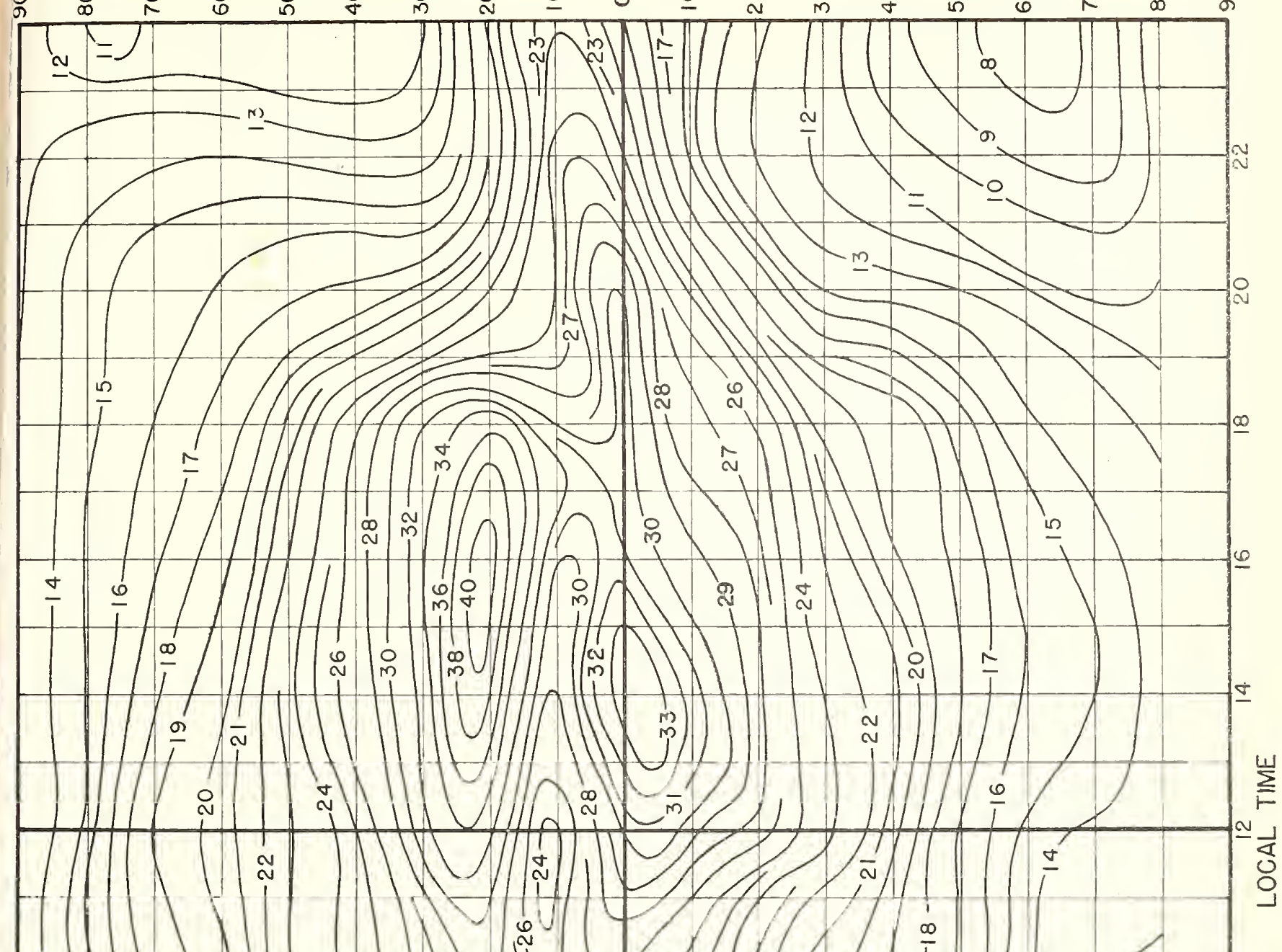

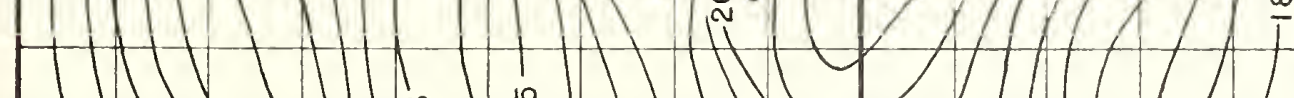
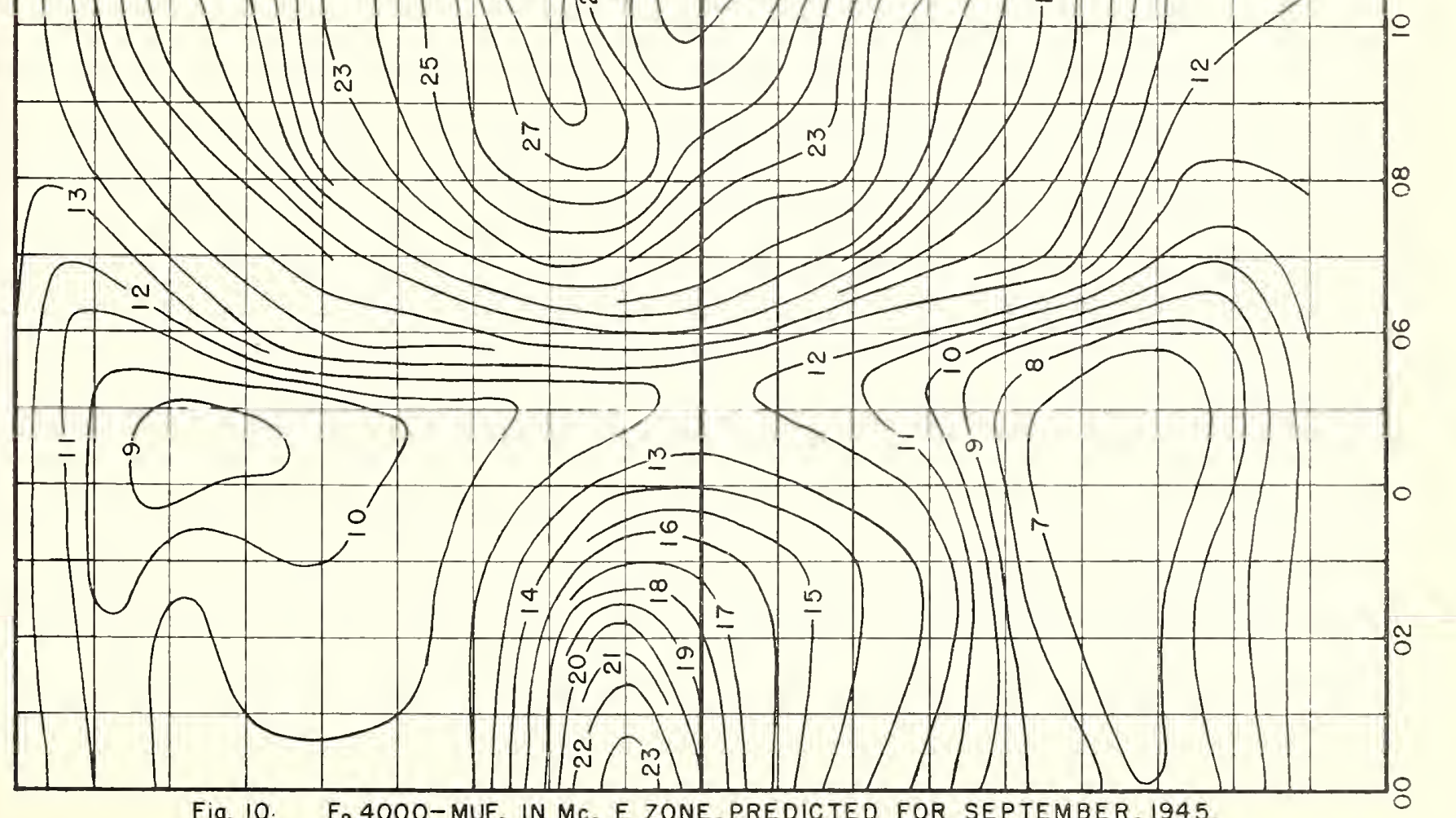

Fig. 10. F $4000-M U F$, IN MC, E ZONE, PREDICTED FOR SEPTEMBER, 1945 


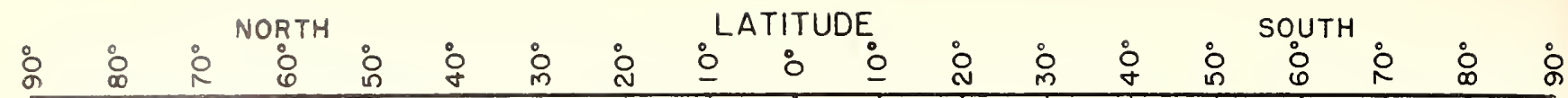

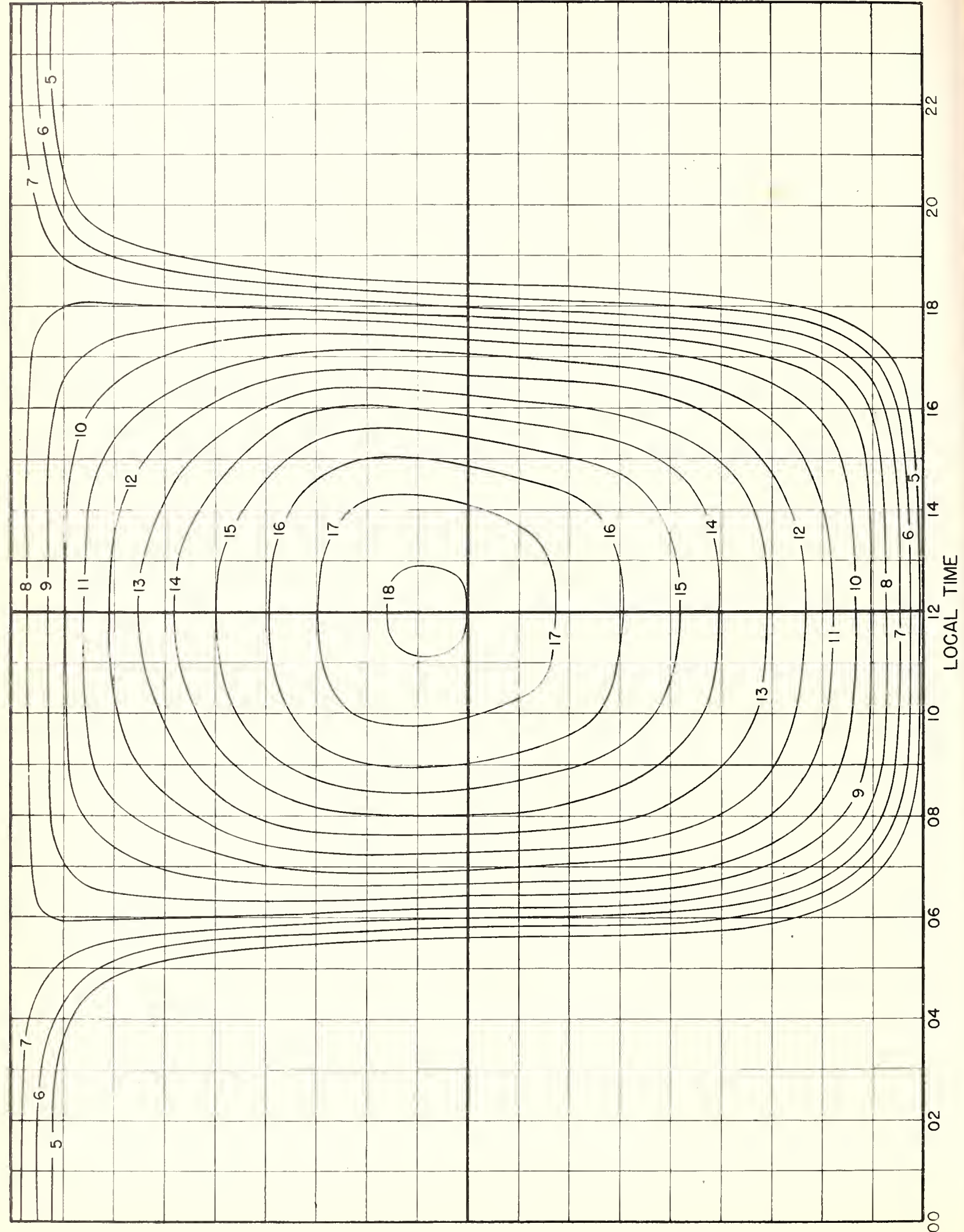




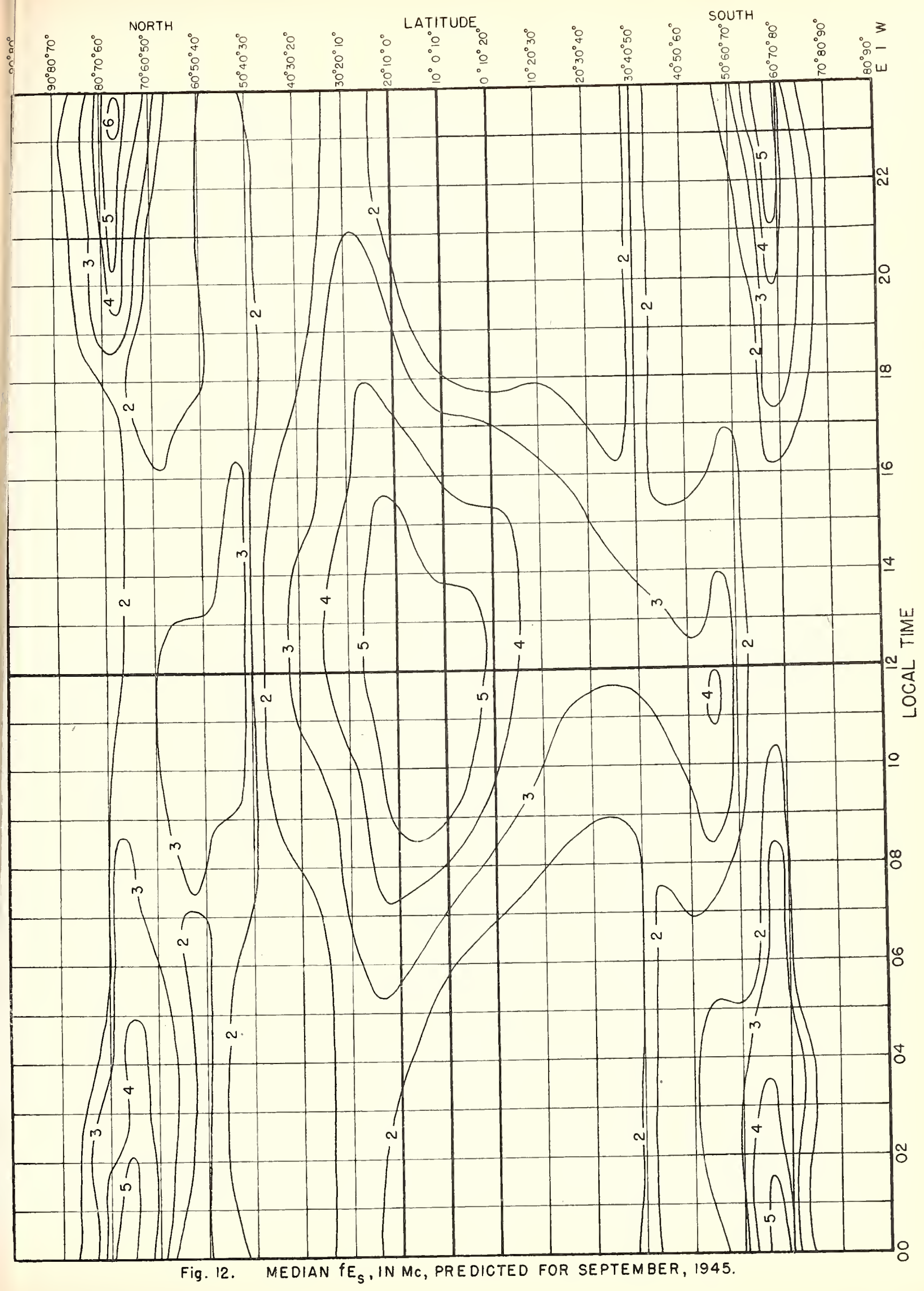




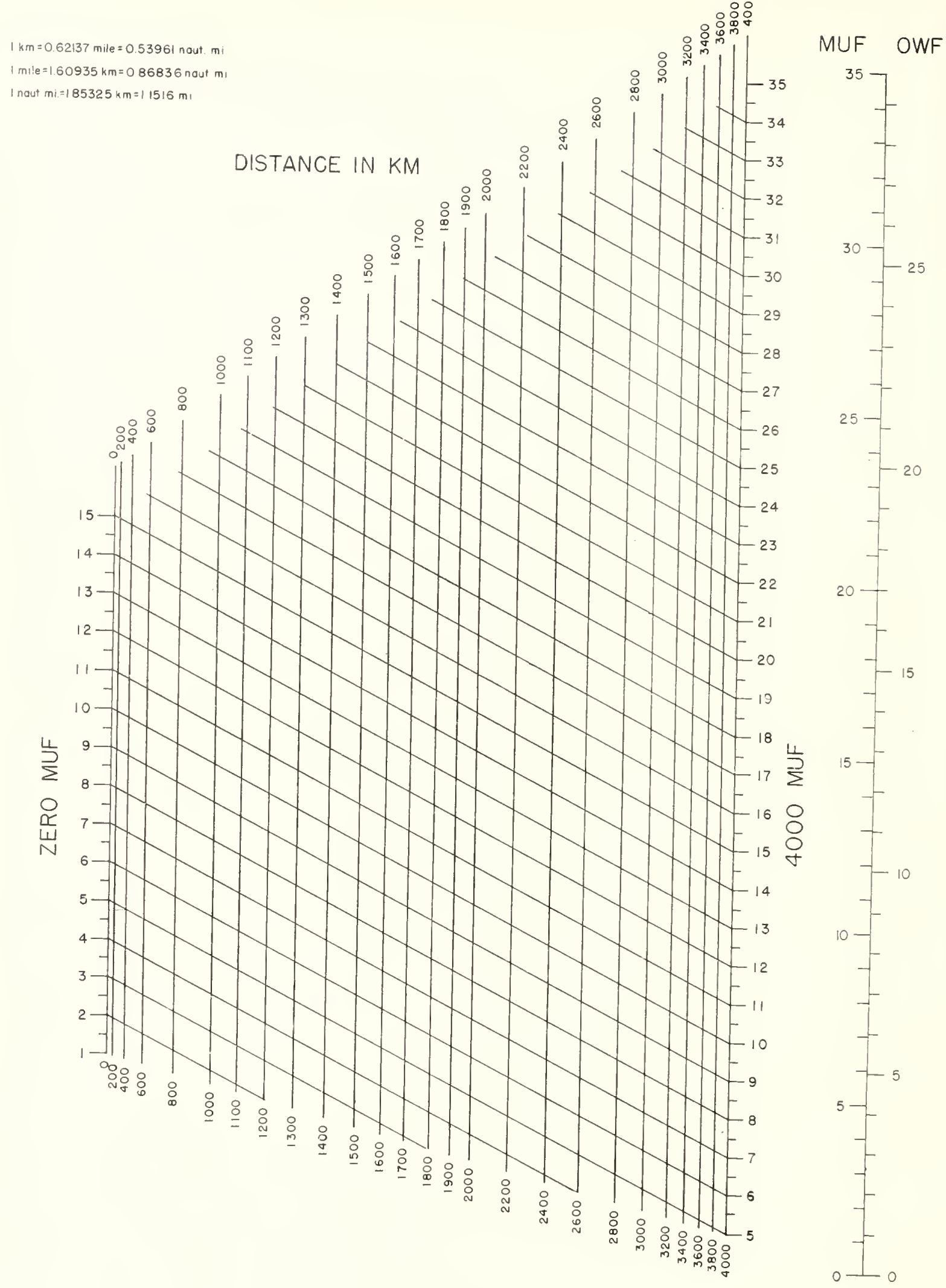

FIG.13. NOMOGRAM FOR TRANSFORMING $F_{2}$-ZERO-MUF AND $F_{2}-4000$-MUF TO EQUIVALENT MAXIMUM USABLE FREQUENCIES AT INTERMEDIATE TRANSMISSION DISTANCES; CONVERSION SCALE FOR OBTAINING OPTIMUM WORKING FREQUENCIES. 


\section{0-Km E muf,}

$\mathrm{MC}$

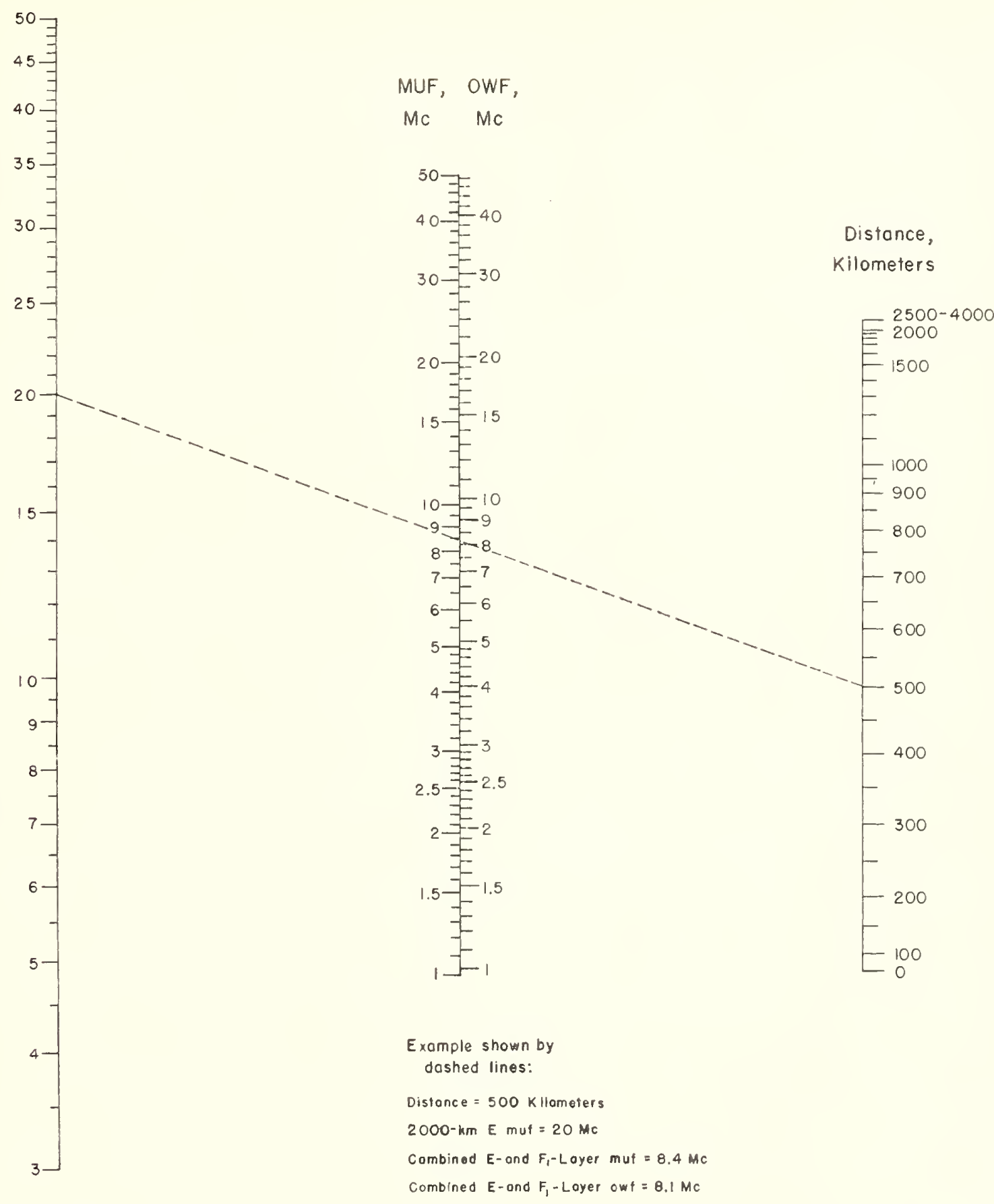

$1 \mathrm{~km}=0.62137$ mile $=0.53961$ nout. mi. 1 mile $=1.60935 \mathrm{~km}=0.86836$ nout. $\mathrm{mi}$. I nout. $\mathrm{mi} .=1.85325 \mathrm{~km}=1.1516 \mathrm{mi}$ 


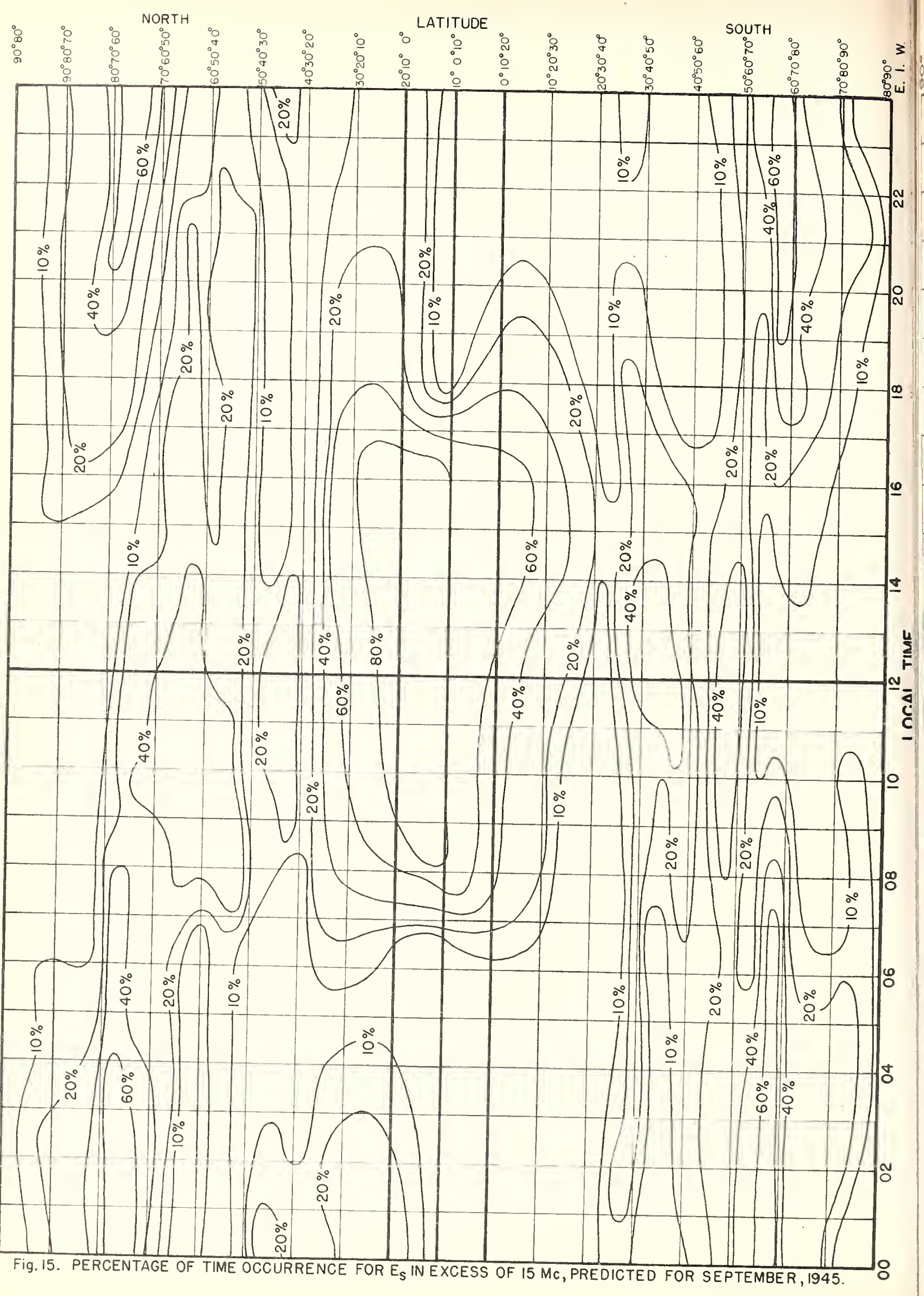





\section{IRPL REPORTS}

Daily:

Telephoned and telegraphed reports of ionospheric, solar, geomagnetic, and radio propagation data from various places.

Radio disturbance warnings.

Semiweekly:

IRPL-J. Radio Propagation Forecast.

Semimonthly:

IRPL-Ja. Semimonthly Frequency Revision Factors for IRPL Basic Radio Propagation Prediction Reports. (Issued with IRPL-J series from 4 to 7 days in advance).

Monthly:

IRPL-D. Basic Radio Propagation' Predictions-Three months in advance. (War Dept. TB 11-499-monthly supplements to TM 11-199; Navy Dept. DNC-13-1 ( ), monthly supplements to DNC-13-1.)

- IRPL-F. Ionospheric Data.

Bimonthly:

IRPL-G. Correlation of D. F. Errors With Ionospheric Conditions.

Quarterly:

IRPI-A. Recommended Frequency Bands for ships and Aireraft in the Atlantic and Pacific.*

IRPL,B. Recommended Frequency Bands for Submarines in the Pacific.

IRPL-H. Frequency Guide for Operating Personnel.*

IRPL-M. Frequency Guide for Merchant Ships.

Special Reports, eic.:

IRPL Radio Propagation Handbook, Part 1. (War Dept. TM 11-499; Navy Dept. DNC 13-1.)

IRPL-C1 through C61. Reports and papers of the International Radio Propagation Conference, 17 April to 5 May 1944.

IRPL-R. Unscheduled reports:

R1. Maximum Usable Frequency Graph Paper.

$\mathrm{R} 2$ and R3. Obsolete.

R4. Methods Used by IPPL for the Prediction of Ionosphere Characteristics and Maximum Usable Frequencies.

R5. Criteria for Ionospheric Storminess.

R6. Experimental studies of ionospheric propagation as applied to a navigation system.

R7. Further studies of ionospheric propagation as applied to a navigation system.

R8. The Prediction of Usable Frequencies Over a Path of Short or Medium Length, Including the Effects of Es.

R9. An Automatic Instantaneous Indicator of Ship Distance and MUF.

R10. A method for study of the ionosphere.

IRPL-T. Reports on Tropospheric Propagation.

T1. Radar Operation and Weather. (Superseded by JANP 101.)

T2. Radar coverage and weather. (Superseded by JANP 102,)

*Now published only by U. S. Nary in NONREGISTERED PUBLICATIONS MEMORANDA (NRPM). 
